\title{
Procesos de difusión residencial en antiguas capitales comarcales. Colmenar Viejo (Madrid)
}

RESUMEN

La región metropolitana de Madrid representa un caso emblemático en el debate contemporáneo sobre la dispersión residencial metropolitana, por la variedad de situaciones que conforman el armazón del hábitat unifamiliar. En este contexto tan diversificado se pretende destacar el caso de Colmenar Viejo, municipio situado en la Cuenca del Manzanares, al norte de Madrid capital, que se configura en la actualidad como un centro híbrido entre sus ambiciones históricas de capital comarcal, rasgos de ciudad dormitorio y atisbos de una evolución hacia un modelo de sub-centro metropolitano.

\section{RÉSUMÉ}

La région métropolitaine de Madrid représente un cas emblématique au sein du débat contemporain sur la dispersion résidentielle métropolitaine, par la variété des configurations de la structure de l'habitat pavillonnaire. Dans ce contexte hétérogène il s'agit de s'intéresser au cas de Colmenar Viejo, commune située dans le bassin del Manzanares, au nord de la capitale de Madrid, centre hybride entre ses ambitions historiques de capitale régionale, ses caractéristiques de cité dortoir et une possible évolution vers un modèle de centre métropolitain secondaire.

\section{INTRODUCCIÓN}

$L$ a dispersión urbana es un fenómeno global que ha afectado a las grandes metrópolis a nivel mundial en las últimas décadas, con muchas diferencias entre sí originadas por las condiciones de cada lugar, difuminando la ciudad en el campo e invadiendo áreas cada vez más extensas y lejanas. La especial importancia de los suburbios y las áreas periurbanas (Fernández, 1986) en los ámbitos metropolitanos se encuentra bien representada en la literatura reciente, utilizando términos como
Abstract

The Madrid metropolitan region represents an emblematic case study within the contemporary debate on metropolitan residential dispersal, due to the diversity of local situations through which single-family housing development is shaped. Within such a diversified context, the municipality of Colmenar Viejo should be given special attention. Situated in the Manzanares basin, North of Madrid, Colmenar is currently a hybrid between its historical ambitions of market town, certain dormitory-town features and hints of an evolution towards a metropolitan sub-centre.

\section{Palabras Clave/Mots ClÉ/Keywords}

Región Metropolitana de Madrid, ciudad difusa, vivienda unifamiliar, suburbanización.

Région métropolitaine de Madrid, ville diffuse, habitat pavillonnaire, suburbanisation.

Madrid metropolitan region, urban sprawl, single-family housing, suburbanization.

urban sprawl (Whyte, 1958, p. 134; Soule, 2005, p. 3; EEA, 2006, p. 6), «ciudad dispersa» (Monclús, 1998), «difusa» Indovina, 1990) o «fragmentada» (Ponce, 2006), aplicados a contextos de naturaleza muy distinta, que tienen en común una idea general de descentralización de población y actividades.

En este sentido, procede destacar la especificidad del modelo difuso madrileño, que representa un caso emblemático y significativo en el debate contemporáneo sobre los procesos de difusión a escala metropolitana. Para entender dicha especificidad, el proceso de desconcentra- 


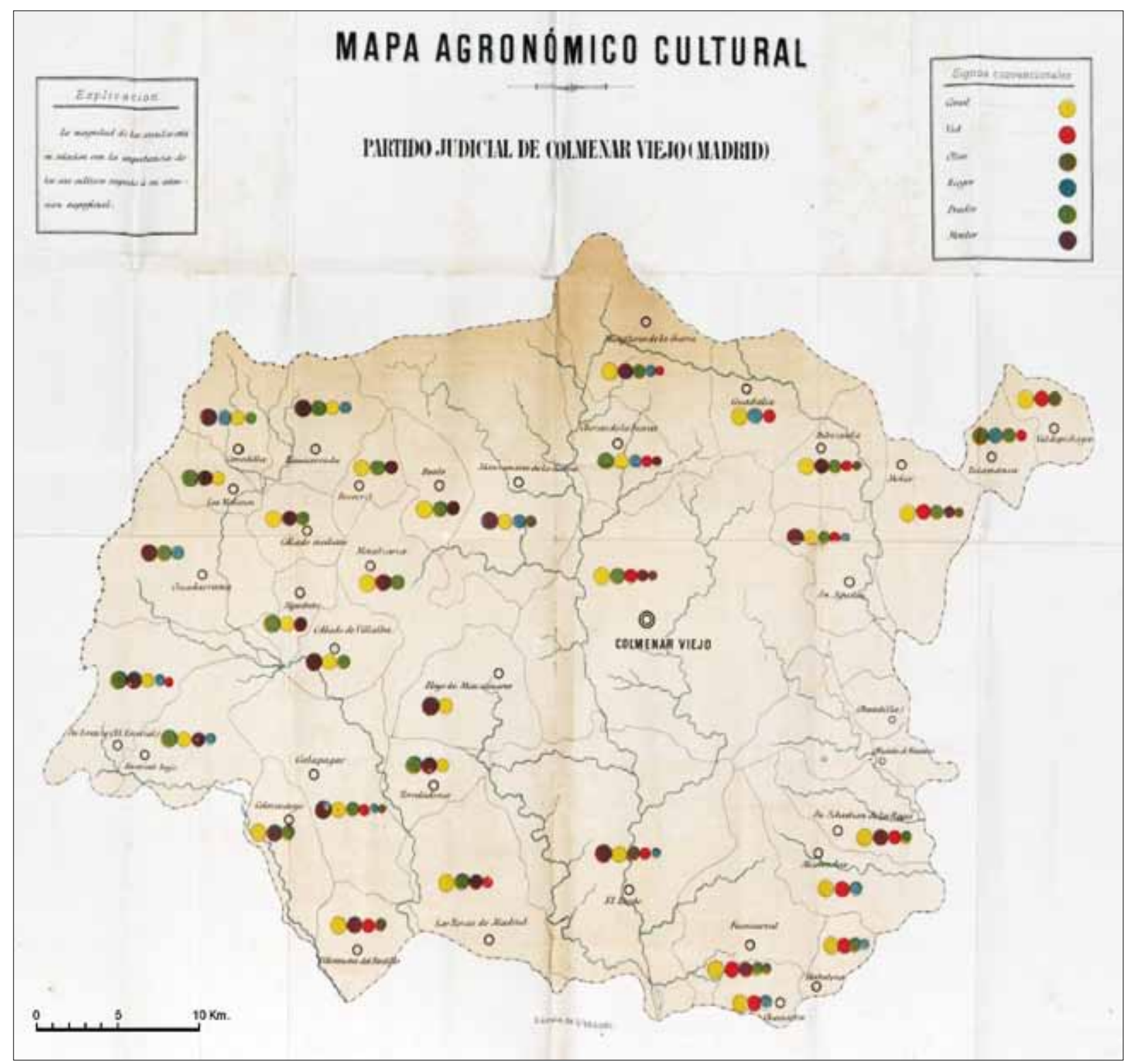

FIG. 1. Mapa agronómico cultural. Partido judicial de Colmenar Viejo (1884). Escala original 1:150.000, de la reproducción 1:417.865. Fuente: Biblioteca Regional de Madrid.

ción residencial ha de ser considerado parte integrante de unas dinámicas más complejas que han dado lugar, con diferentes ritmos y pautas, a una redistribución de población, empleo y usos del suelo por todo el territorio regional (Santiago, 2007; Zárate, 2003; Valenzuela, 2011). Los procesos de suburbanización y periurbanización en la región metropolitana de Madrid son relativamente recientes y, aunque «la región urbana de Madrid viene configurándose como tal desde los años sesenta», es cierto que «la intensidad de sus transformaciones territoriales se ha acelerado desde los últimos años ochenta y en la década de los noventa del siglo xx» (López de Lucio, 2003 , p. 124). Hasta entonces, la capital española seguía básicamente un patrón de desarrollo de tipo monocéntrico. En la segunda parte de los ochenta se comienza a producir un fenómeno de desconcentración de población y actividades que afecta a distintas funciones, incluyendo la residencial, protagonizada por una difusión en el territorio de la vivienda unifamiliar. El fenómeno de difusión regional de las viviendas unifamiliares se incardina, por 
CuAdro 1. Distribución porcentual de la población activa por sectores de actividad entre los años sesenta y setenta

\begin{tabular}{llccccc|}
\hline \multicolumn{1}{c}{ Sectores } & & 1960 & & 1970 & & 1975 \\
\cline { 1 - 1 } \cline { 5 - 6 } \cline { 5 - 6 } \cline { 5 - 6 } Primario & & 45 & & 10 & & 9 \\
Secundario & & 11 & & 24 & & 22,2 \\
Construcción & & 17 & & 31 & & 27,4 \\
Terciario & & 27 & & 35 & & 40,5 \\
\hline
\end{tabular}

Fuente: Coplaco (1981, p. 16).

lo tanto, en el periodo de transición «desde un modelo de área metropolitana hasta otro que podemos definir como de región metropolitana», el cual, por lo que respecta al mercado residencial, tiene como peculiaridad «que los distintos espacios que lo constituyen se encuentren unidos bajo un mismo mercado residencial lo cual sucede porque en ellos existe una misma cadena de sustitución que permite que los cambios residenciales se puedan producir sobre el conjunto de municipios que se pueden englobar dentro del área de influencia de la región metropolitana» (Leal y Cortés, 1995, pp. 26-27).

El proceso de difusión residencial metropolitana en Madrid, pese a que puedan existir casos puntuales asimilables al modelo residencial anglosajón o norteamericano (nos referimos, por ejemplo, a las urbanizaciones de alto standing creadas en los años sesenta y setenta en el corredor noroeste de la comunidad de Madrid), ha dado lugar a un tipo de hábitat unifamiliar absolutamente original y específico. El desarrollo de la vivienda unifamiliar en la región metropolitana de Madrid se caracteriza por la localización mayoritaria de los asentamientos alrededor de núcleos urbanos preexistentes. Por lo tanto, podemos afirmar que, aunque existe un proceso de difusión a escala metropolitana, éste da lugar a una forma de difusión concentrada, en la cual «los nuevos desarrollos se han adosado a los viejos cascos o a sus ensanches, dado que la implantación residencial difusa en forma de urbanizaciones aisladas limita ahora su papel, básicamente, a colmatar las heredadas de décadas anteriores» (Valenzuela, 2011, p. 220). La ubicación de los desarrollos de vivienda unifamiliar en el entorno de núcleos preexistentes puede ser beneficiosa para los residentes que pueden utilizar los servicios y los equipamientos de sus alrededores, frecuentemente situados a distancia peatonal y permite diferenciar claramente el modelo residencial difuso madrileño del sprawl norteamericano.

La generalización territorial del desarrollo de la vivienda unifamiliar en la comunidad de Madrid ha dado

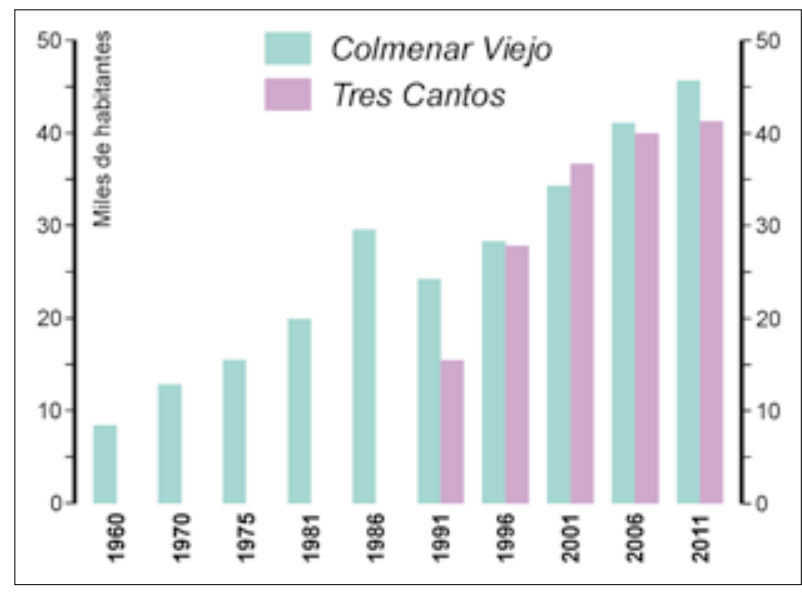

FIg. 2. Población de derecho desde 1960. Fuente: Instituto de Estadística de la Comunidad de Madrid. Elaboración propia.

lugar a formas de asentamiento más compactas (Canto, 1987, p. 396) y similares entre ellas, predominando a partir de los años ochenta los chalés adosados (Valenzuela, 2003, p. 120). En la actualidad, lo que marca realmente la diferencia entre los asentamientos de viviendas unifamiliares de las zonas sur, norte, este y oeste de la comunidad de Madrid es el hecho de que «las estructuras urbanas sobre las que se desarrollan son completamente distintas en unos municipios que en otros» (Leal y Cortés, 1995, p. 23). De hecho, la existencia de un abanico relativamente amplio de realidades locales a la escala subregional permite destacar determinados rasgos meso y microterritoriales y contextualizar el desarrollo de la vivienda unifamiliar en función del lugar donde se asienta. Un caso específico que merece ser destacado dentro del ámbito de la comunidad de Madrid es el de la difusión residencial en antiguas capitales comarcales. Se trata de municipios que actualmente se caracterizan por su carácter híbrido, presentando al mismo tiempo ciertos rasgos de diversificación funcional ligados a su condición histórica de capital comarcal y otros de núcleo dormitorio, resultantes de las dinámicas residenciales recientes a nivel metropolitano.

El municipio de Colmenar Viejo, situado tan sólo a treinta kilómetros de Madrid capital, representa un ejemplo de un núcleo urbano que aúna rasgos de pueblo dormitorio, acentuados sobre todo a partir de los años ochenta del siglo pasado, con una tradición histórica de cabecera comarcal y de centro de servicios para los municipios de su área de influencia, al mismo tiempo que manifiesta la presencia de signos aislados y muy incipientes de un proceso de diversificación funcional que es típico de su condición de subcentro metropolitano. No 
CuAdro 2. Polígonos industriales históricos en Colmenar

\begin{tabular}{|c|c|c|c|c|}
\hline Nombre polígono & Año plan parcial & Superficie $\left(\mathrm{m}^{2}\right)$ & Tipo de actividad & Grado de ocupación según PGOU 1987 \\
\hline Industrial Sureste (La Mina) & 1974 & 246.139 & Industria en general & \\
\hline Artesanal & 1975 & 45.388 & $\begin{array}{l}\text { Industria artesanal (talleres, } \\
\text { almacenes y pequeña industria) }\end{array}$ & $30 \%$ de superficie total \\
\hline Industrial Sur & 1976 & 642.959 & Industria en general & \\
\hline Agropecuario & 1977 & 37.665 & Industria agropecuaria & \\
\hline
\end{tabular}

Fuente: PGOU (1987) y PAI Norte.

Cuadro 3. Población de derecho desde 1960

\begin{tabular}{|c|c|c|c|c|c|c|c|c|c|c|}
\hline & 1960 & 1970 & 1975 & 1981 & 1986 & 1991 & 1996 & 2001 & 2006 & 2011 \\
\hline Colmenar Viejo & 8.483 & 12.826 & 15.502 & 19.839 & 29.495 & 24.202 & 28.328 & 34.194 & 40.878 & 45.468 \\
\hline Tres Cantos & - & - & - & - & - & 15.431 & 27.715 & 36.598 & 39.826 & 41.065 \\
\hline
\end{tabular}

Fuente: Instituto de Estadística de la Comunidad de Madrid. Elaboración propia.

cabe duda de que por su papel histórico Colmenar Viejo tiene un nivel de complejidad y de interés superior a los municipios limítrofes incluidos en su área de influencia comarcal y que al mismo tiempo se diferencia de todos aquellos pequeños municipios situados alrededor del corredor de la autovía A-6 (Madrid-La Coruña), caracterizados tradicionalmente por segundas residencias de cierto nivel cualitativo. En los siguientes apartados se intentará destacar las peculiaridades del municipio de Colmenar Viejo, su importancia histórica y su variedad morfotipológica de asentamientos de vivienda unifamiliar, subrayando la influencia que han tenido las distintas fases y épocas de desarrollo urbanístico así como la importancia de los instrumentos de planificación de carácter municipal.

\section{COLMENAR VIEJO ENTRE LA TRADICIÓN RURAL Y LAS ASPIRACIONES DE CABECERA COMARCAL HASTA LA DÉCADA DE 1980}

Colmenar Viejo es un municipio que ha tenido históricamente una función de capitalidad comarcal, siendo el centro de referencia para los municipios de su alrededor. El plan general vigente define el ámbito de influencia comarcal de Colmenar Viejo incluyendo los siguientes municipios: Manzanares el Real, Miraflores de la Sierra, Guadalix de la Sierra, Soto del Real, El Boalo y San Agustín del Guadalix. Su capitalidad comarcal deriva de la importancia histórica del municipio, que surgió en tiempos medievales cuando ocupaba un papel importante dentro del territorio del Real de Manzanares, realengo constituido por Alfonso X el Sabio en 1268 con el fin de aplacar los enfrentamientos que ocurrían entre segovianos y madrileños por tener el control de los pastos y henos del área ${ }^{1}$. Los segovianos en concreto dejaron cierta huella en este territorio por su tradición ganadera bovina y ovina, que caracterizó la economía de la zona durante siglos gracias a la existencia de abundante cantidad de tierra utilizada para pastos y producción de lana. La función de cabecera comarcal se ha mantenido a lo largo de los siglos, proporcionando desde el siglo xVIII servicios y empleo a los municipios cercanos y ejerciendo de cabecera de partido en el siglo XIX (Fig. 1)2.

\footnotetext{
1 Sucesivamente Juan II otorgó el título de marqués de Santillana a don Íñigo López de Mendoza, que tomó plena posesión de este territorio y cuyos descendientes ostentarán el título de duques del Infantado. La vinculación del Real de Manzanares a la casa del Infantado permanecerá hasta el siglo XIx. Para más información sobre este tema, véase $<$ https://sites.google.com/site/sociedadcamineradereal/porque-real-del-manzanares-1 $>$. Sin embargo, cabe destacar que en 1504 se otorgó a Colmenar el privilegio de villazgo quedando segregada de la jurisdicción de Manzanares.

2 Parece interesante mencionar una descripción de 1890 del pueblo, que resume sus características en este periodo: «El partido judicial de Colmenar Viejo es uno de los más productores de la provincia, siendo la ganadería el primero y más importante ramo de la producción agrícola. [...] La industria se halla en estado embrionario, y muy por bajo de la que ofrecen otros partidos judiciales de la provincia. Hay, sin embargo, varias e importantes fábricas de curtidos en la capital del partido [...]. El comercio está en relación con la agricultura y con la industria. Redúcese a la exportación de leches, caza, que abunda mucho, carnes muertas, ganados y algunos cereales, que por lo común se envían a Madrid» (Ayala y Raya, 1890, pp. 38-41).
} 


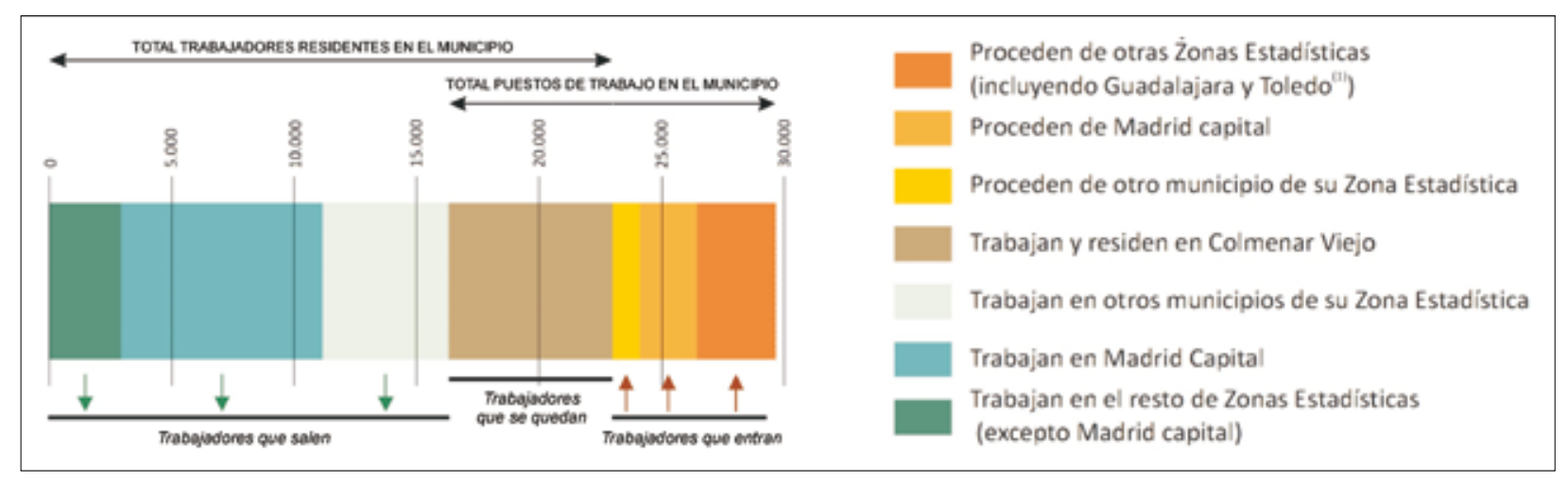

FIG. 3. Trabajadores por cuenta ajena que residen, entran y salen de Colmenar Viejo. Fuente: Atlas de la movilidad residencia-trabajo de la Comunidad de Madrid (2010).

La importancia de este centro en relación con los municipios limítrofes y también con Madrid capital fue incrementada a comienzos del siglo xx por las mejoras de la accesibilidad a través de la construcción del ferrocarril de vía estrecha. En 1911 la Compañía Madrileña de Urbanización inauguraba la línea Madrid-Colmenar Viejo, que no servía sólo para el transporte de viajeros, sino, sobre todo, de mercancías, destacando el transporte de leche y de la piedra, mayoritariamente utilizada para fabricar adoquines y material para pavimentación de carreteras $^{3}$. En la misma época, pocos años antes (1902), llegaban a Colmenar las obras del canal de Santillana, así llamado por el nombre del homónimo marqués descendiente de los duques del Infantado y creador de la Sociedad Hidráulica (1905), que abastecía una parte de los barrios de la zona norte de Madrid.

Tal y como se explica en la memoria del plan general de 1987 (Ayuntamiento de Colmenar Viejo, 1987, p. 42), la configuración económica de Colmenar hasta los años sesenta del siglo xx se basaba en actividades agrarias, extractivas y comerciales, siendo además el cuarto municipio de la provincia en cuanto a peso demográfico. En los años sesenta se produjo una modificación en la estructura socioeconómica del pueblo, debida a varios factores: la lejanía respecto a la oferta residencial de la N-VI hizo que no se produjera el boom económico que aconteció en otros municipios en aquella época; la presencia de un medio ambiente atractivo sirvió, sin embargo, de acicate para la construcción de segundas residencias destinadas a segmentos de la clase media madrileña que no podían permitirse una vivienda de este tipo en los municipios del

\footnotetext{
3 Más información en <www.spanishrailway.com/capitulos_html/ferrocarril demadridacolmenarviejo.htm $>$.
}

corredor de la N-VI; gradualmente una parte de empleados del sector primario se incorporó al sector terciario y al de la construcción. Este último sector en concreto al final de la década tuvo un papel fundamental en la economía local, puesto que sus trabajadores se dedicaron a la realización de obras tan importantes como los canales de abastecimiento de agua de Madrid, la vía férrea que conectó Madrid con Burgos (1968), sin olvidar la construcción de las anteriormente mencionadas residencias secundarias. La fase de auge de la construcción en Colmenar duró de 1960 a 1975 cuando parte de sus empleados pasó al sector terciario. La tradición de Colmenar como centro ganadero de la sierra madrileña de hecho perduró hasta esa fecha (y sigue existiendo actualmente); no es casualidad que la única industria que existía con anterioridad a 1960 era alguna fábrica láctea aislada y el matadero frigorífico Giresa (Coplaco, 1981, p. 16-23). El cuadro 1 deja constancia de la disminución de la población activa en el sector primario y el incremento de los demás en este periodo.

Algunos años más tarde el desdoblamiento de la carretera 607 Madrid-Colmenar (1974) incrementó la accesibilidad y contribuyó también a mantener activo el mercado de la segunda residencia. Sin embargo, después de la operación urbanística que llevó a la construcción de la Ciudad Nueva de Tres Cantos (1971) y de la creación en 1968 de algunas urbanizaciones separadas del continuo construido del núcleo histórico (Valdelagua y Ciudalcampo y Soto de Viñuelas), el pueblo empezó a ser también lugar de residencia permanente para ciertos grupos sociales de clase media provenientes de Madrid. Todas estas actuaciones, junto con las instalaciones militares del «CIR núm. 1» (Centro de Instrucción de Reclutas), la base de helicópteros situada a cuatro kilómetros del núcleo, en la dehesa del Navallar, utilizada para 
CuAdro 4. Población residente, vinculada y tasa de vinculación en 2001

\begin{tabular}{|c|c|c|c|c|}
\hline Municipio & Residentes & Vinculados no residentes & TOTAL & Tasa de vinculación \\
\hline \multirow{3}{*}{ Colmenar Viejo } & 35.181 & 7.977 & 43.158 & \multirow{3}{*}{$122,67 \%$} \\
\hline & $\%$ Residentes & $\%$ Vinculados no residentes & TOTAL \% & \\
\hline & 81,52 & 18,48 & 100,00 & \\
\hline
\end{tabular}

Fuente: INE. Elaboración propia.

CuAdro 5. Resumen de los ejemplos mencionados anteriores al Plan General de 1969

\begin{tabular}{|c|c|c|c|c|c|c|}
\hline Tipo de actuación & Nombre & Fecha & Promotor & Sup. $\left(\mathrm{m}^{2}\right)$ & $\begin{array}{l}\text { Parc. mín. } \\
\text { (PGOU 2002) }\end{array}$ & $\begin{array}{c}\text { Tipología } \\
\text { (PGOU 2002) }\end{array}$ \\
\hline Colonias del ensanche & Colonia La Paz & 1957 & D. G. Regiones Dev. & N/D & La existente & - \\
\hline \multirow{2}{*}{$\begin{array}{l}\text { Parcelaciones } \\
\text { periféricas perimetrales }\end{array}$} & La Magdalena & $\mathrm{N} / \mathrm{D}$ & N/D & $\mathrm{N} / \mathrm{D}$ & $300 \mathrm{~m}^{2}$ & Aislada \\
\hline & Los Remedios & 1959 & Sociedad anónima & N/D & $250 \mathrm{~m}^{2} \mathrm{o}$ exist. & Pareada/adosada \\
\hline \multirow{4}{*}{$\begin{array}{l}\text { Urbanizaciones } \\
\text { periféricas perimetrales }\end{array}$} & Colina de las Torres & $1964^{*}$ & Particular & $\mathrm{N} / \mathrm{D}$ & $400 \mathrm{~m}^{2}$ & Aislada \\
\hline & Dos Castillas & 1960 & Soc. anón. ind. & N/D & $250 \mathrm{~m}^{2}$ & Pareada \\
\hline & San Crispín & $\mathrm{N} / \mathrm{D}^{* *}$ & $\mathrm{~N} / \mathrm{D}$ & $\mathrm{N} / \mathrm{D}$ & $1.000 \mathrm{~m}^{2 * * *}$ & Aislada \\
\hline & Las Vegas & 1966 & Girón, S. A. & $\mathrm{N} / \mathrm{D}$ & $500 \mathrm{~m}^{2}$ & - \\
\hline \multirow{4}{*}{$\begin{array}{l}\text { Urbanizaciones aisladas } \\
\text { del casco }\end{array}$} & Ciudalcampo & 1968 & Ciudalcampo, S. A. & 1.035 .895 & $2.500 \mathrm{~m}^{2}$ o ex. & Aislada \\
\hline & S. de Viñuelas & 1968 & Urb. Sta. Mónica & 2.161 .688 & $1.500 \mathrm{~m}^{2}$ & Aislada \\
\hline & Punta Galea & 1968 & $\mathrm{~N} / \mathrm{D}$ & 30.900 & $\mathrm{~N} / \mathrm{D}$ & Pareada \\
\hline & Valdelagua & 1968 & C. Merc. Valdelagua & $829.153^{* * * *}$ & $2.000 \mathrm{~m}^{2}$ & Aislada \\
\hline \multicolumn{7}{|c|}{ 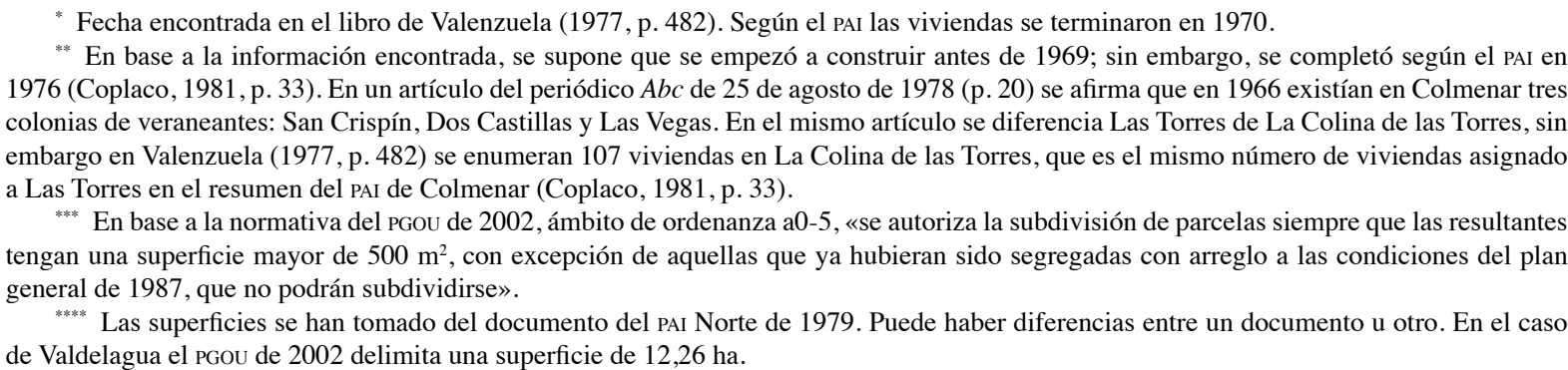 } \\
\hline
\end{tabular}

Fuentes: PAI Norte, documento resumen del PAI de Colmenar Viejo, Valenzuela (1977), BOE.

prácticas militares, y las servidumbres de infraestructuras contribuyeron a configurar la que se ha definido como «colonización del espacio municipal del Colmenar por Madrid capital» (Ayuntamiento de Colmenar Viejo, 1987, p. 43). Esto implicó la ocupación de áreas de cierto valor medioambiental con funciones más metropolitanas que locales o comarcales, sin compensar adecuadamente las cargas que ha soportado el municipio de Colmenar con unos supuestos beneficios. Este proceso ha llevado a la definición de iniciativas dependientes de instrumentos legislativos ajenos al ayuntamiento, siendo éste el caso de Tres Cantos, creada como actuación urbanística urgente mediante el decreto-ley $1.321 / 1971^{4}$ para absorber

\footnotetext{
4 Las actuaciones urbanísticas urgentes se referían a operaciones urbanísticas del Instituto Nacional de Urbanización, que pretendía hacer frente al boom demográfico y la demanda de vivienda generada en la década de los sesenta.
} 


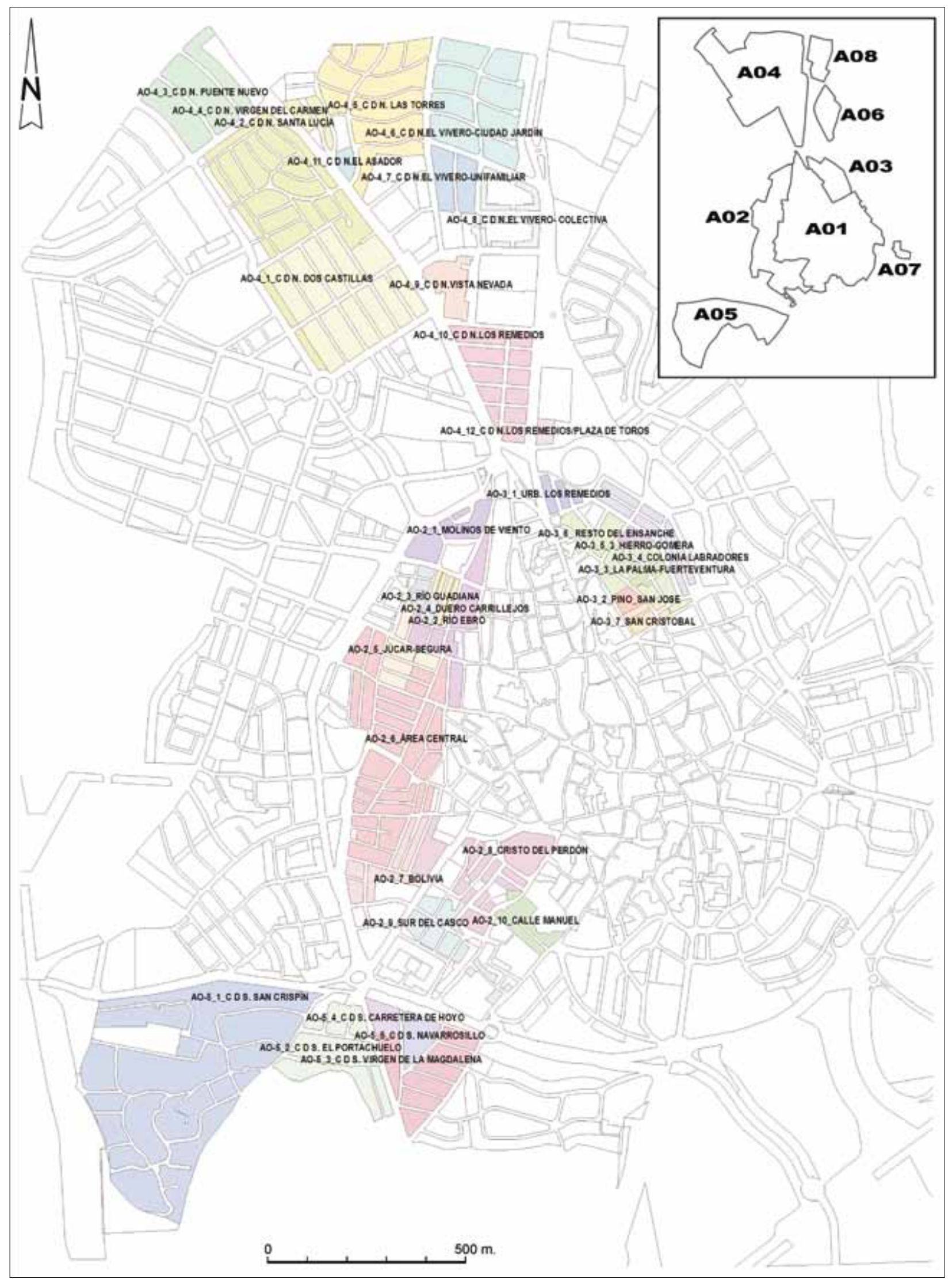

FIG. 4 Áreas de ordenanza en suelo urbano. Plan general de 2002. Fuente: Plan General de Ordenación Urbana de 2002. Subáreas dentro de las áreas de ordenanza en suelo urbano de Colmenar. Fuente: elaboración propia a partir de una base cartográfica de la Comunidad de Madrid. 

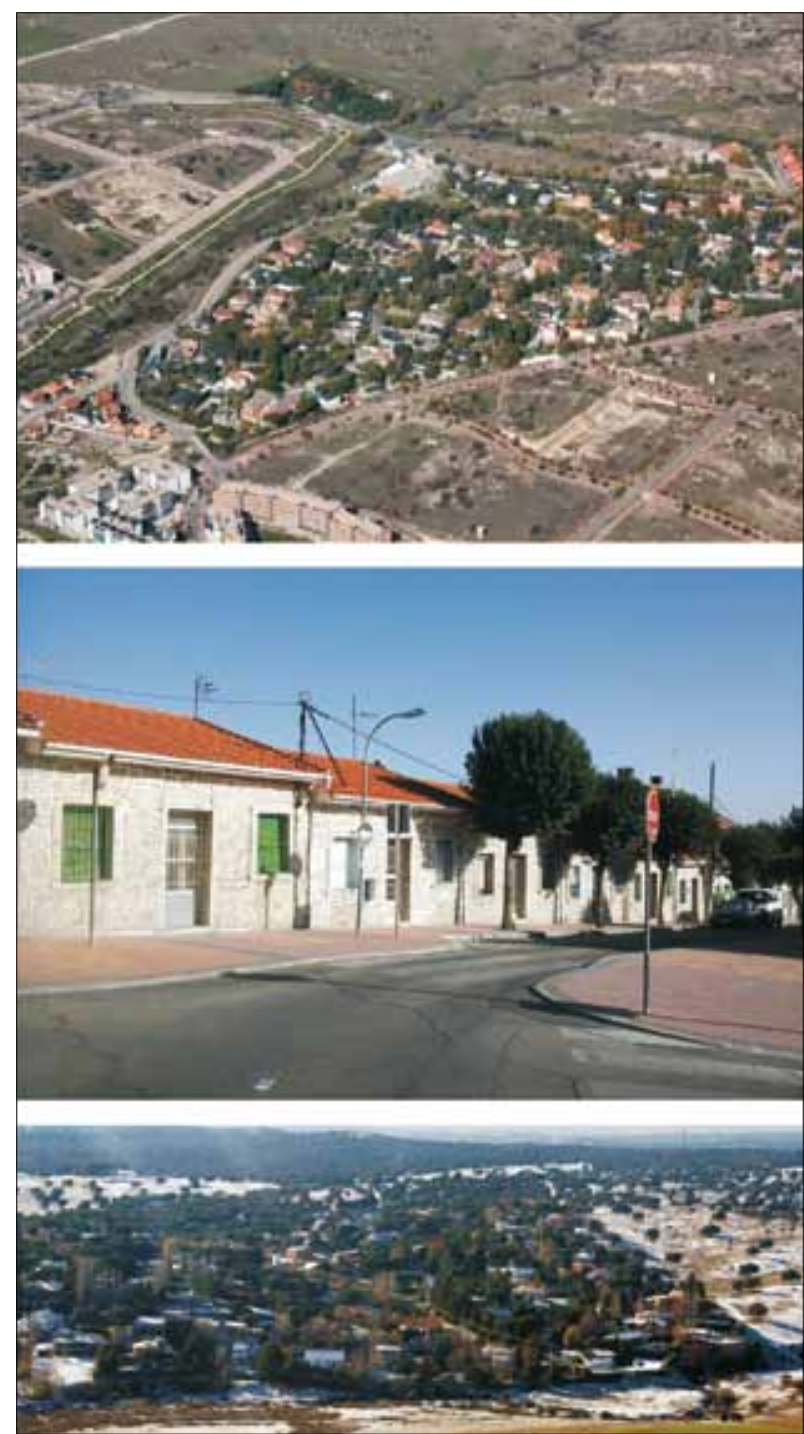

FIG. 5. Arriba, urbanización San Crispín (vista de pájaro). Fotografía de Juan de la Puente; en medio, colonia La Paz (vista desde la calle). Fotografía del autor; abajo urbanización Valdelagua (vista de pájaro). Fotografía de Juan de la Puente.

parte de la presión poblacional inmigratoria orientada hacia Madrid. En su proyecto original se preveía un asentamiento para 140.000 habitantes. Tal y como se lee en la memoria del plan general de 2002, en el plan general municipal de 1969 se había incluido la concepción de crear este nuevo asentamiento «para servir los intereses del área metropolitana de Madrid, antes que para atender las necesidades de un centro comarcal emergente», y de hecho su posterior segregación (1991) abandonó «el núcleo tradicional de Colmenar Viejo a una perspectiva marginal en la previsión del crecimiento metropolitano» (Ayuntamiento de Colmenar Viejo, 2002, p. 4).

Colmenar Viejo en los años ochenta seguía siendo cabecera comarcal; sin embargo, se manifestaba cierto déficit de servicios para su entorno, con una demanda no del todo satisfecha de comercio, enseñanza, actividades socioculturales y sanidad ${ }^{5}$. Pese a que se generó una oferta de segunda y primera residencia para los madrileños, la economía colmenareña no evolucionó de manera simultanea para cubrir las nuevas exigencias de los nuevos residentes y se registró cierto desequilibrio entre empleo y población activa (según el plan general de 1987, sólo el $40 \%$ de la población activa tenía un empleo local). Por lo que concierne a las actividades, en el sector de la construcción se amplió el abanico de promotores que provenían ya de un mercado que no era exclusivamente local en detrimento de los intereses de los constructores colmenareños, habiendo hasta aquel momento prevalecido la promoción local de pequeño tamaño; por otro lado, la industria que se implantó en el municipio (véase cuadro 2) no estuvo ligada a las características tradicionales de la población local, al estar orientada hacia una mano de obra cualificada. No obstante, en el documento resumen del PAI de Colmenar (1981) se destaca cómo a finales de los setenta se registró una disminución de agricultores y ganaderos y un incremento de obreros sin especialización que en cierta manera estaban más relacionados con el sector industrial (Coplaco, 1981, p. 22). A finales de los años setenta se construyeron cuatro polígonos, dos para industria en general (La Mina y Polígono Sur) y otros dos para actividades artesanales y agropecuarias. No tuvieron éxito inmediato, como demuestra la memoria del plan general de 1987, en que se afirma que todavía en esa fecha el $70 \%$ de su superficie se encontraba vacía (Ayuntamiento de Colmenar Viejo, 1987, p. 35).

Merece la pena también destacar en este periodo la existencia de cierto nivel de segregación social dentro del mismo municipio: los habitantes de origen colmenareño ocupaban las viviendas del casco antiguo y las de los ensanches del sur y del este; sin embargo, la segunda residencia se situaba al norte y oeste, por ser áreas de mayor calidad ambiental. Esta segregación espacial es significativa por haberse mantenido históricamente y estar presente todavía hoy en día.

5 En el documento del PAI de Colmenar de 1981 se reserva especial atención al déficit a nivel comarcal de equipamiento escolar a nivel de enseñanza media (BUP y FP), habiendo una dotación de carácter local que estaba cubriendo inadecuadamente una demanda proveniente de los municipios cercanos. 
CUADRO 6. Resumen de los ejemplos mencionados posteriores al plan general de 1969

\begin{tabular}{|c|c|c|c|c|c|}
\hline Tipo de actuación & Nombre & Fecha & Sup. $\left(\mathrm{m}^{2}\right)$ & $\begin{array}{l}\text { Parc. mín. } \\
\text { (PGOU 2002) }\end{array}$ & $\begin{array}{l}\text { Tipología permitida } \\
\text { (PGOU 2002) }\end{array}$ \\
\hline \multirow{12}{*}{$\begin{array}{c}\text { Urbanizaciones } \\
\text { periféricas } \\
\text { perimetrales }\end{array}$} & Santa Lucía & 1975 & 94.880 & $400 \mathrm{~m}^{2}$ & Aislada o pareada \\
\hline & Prado Rosales & 1975 & 81.521 & $200 \mathrm{~m}^{2}$ & Adosada, aislada, pareada \\
\hline & El Pozanco & 1977 & 91.200 & $200 \mathrm{~m}^{2}$ & $\mathrm{~N} / \mathrm{D}$ \\
\hline & Puente Nuevo & 1979 & 64.800 & $500 \mathrm{~m}^{2}$ & Aislada \\
\hline & El Olovasio & 1975 & 158.900 & $300 \mathrm{~m}^{2}$ & Pareada o aislada \\
\hline & El Vivero II & 1978 & 86.440 & $\mathrm{~N} / \mathrm{D}$ & Pareada \\
\hline & Doble Rotador & 1975 & 110.400 & $500 \mathrm{~m}^{2}$ & Pareada o aislada \\
\hline & El Portachuelo & 1977 & 21.879 & La existente & Pareada \\
\hline & Sta. Teresa de Ávila & 1975 & 70.832 & $150 \mathrm{~m}^{2}$ & Pareada, adosada \\
\hline & El Redondillo & 1975 & $20.500^{*}$ & $120 \mathrm{~m}^{2}$ & Pareada, adosada \\
\hline & Fuente del Cajón & 1974 & 99.900 & $350 \mathrm{~m}^{2}$ & Pareada, adosada \\
\hline & Fuente Santa & 1976 & 32.710 & $750 \mathrm{~m}^{2}$ & $\mathrm{~N} / \mathrm{D}$ \\
\hline $\begin{array}{l}\text { Urbanizaciones } \\
\text { aisladas del casco }\end{array}$ & El Madroñal de Guadalix & 1972 & 300.027 & $\mathrm{~N} / \mathrm{D}$ & $\mathrm{N} / \mathrm{D}$ \\
\hline \multirow{2}{*}{$\begin{array}{l}\text { Agrupaciones } \\
\text { ilegales }\end{array}$} & Los Chortales & 1974 & 467.000 & 25.000 & Aislada (ilegal) \\
\hline & Los Pajarejos & 1970 & 830.000 & 25.000 & Aislada (ilegal) \\
\hline
\end{tabular}

Fuente: PAI Norte, documento resumen del PAI de Colmenar Viejo, Valenzuela (1977), вOE, Comunidad de Madrid (2006).

\section{RASGOS DE CIUDAD DORMITORIO A PARTIR DE LA DÉCADA DE 1980}

A partir de la consideración del apartado anterior sobre el desequilibrio entre población y empleo que surgió en los años ochenta en Colmenar y de su déficit dotacional con respecto a su función predominante de cabecera comarcal que ejerció claramente hasta esa fecha, se puede empezar a hablar de una gradual transformación del pueblo hacia su actual caracterización como núcleo dormitorio. Esta función prevalece sobre la anterior o, mejor dicho, se presenta de forma híbrida coexistiendo en parte con su papel tradicional de capital comarcal.

Para entender el comienzo de esta fase de transición acontecida a partir de los años ochenta, parece interesante hacer referencia a una serie de datos referidos a esa época. Como se explica en la memoria del plan general de 1987 (Ayuntamiento de Colmenar Viejo, 1987, p. 35), en el período anterior a su aprobación los desequilibrios anteriormente mencionados produjeron intensos movimientos de población, tanto de salida de trabajadores no cualificados como de llegada de nuevos residentes, como corresponde a un municipio dormitorio. Si, por un lado, se generó una emigración de población (mayoritariamente jóvenes y obreros sin cualificar provenientes del sector de la construcción que habían anteriormente dejado su actividad agraria y no encontraban trabajo local), al mismo tiempo se producía una inmigración hacia Colmenar de jóvenes madrileños en busca de una vivienda asequible. Lo más significativo de los datos de este plan general es que de los viajes exteriores al municipio de Colmenar en esa fecha más del $50 \%$ era por motivos de trabajo y de los viajes por trabajo el $80 \%$ tenía como destino Madrid capital. Otro elemento a destacar para poner en evidencia este momento de transformación de Colmenar hacia su configuración como ciudad residencial es el fuerte impacto de la población estacional que representaba todavía a finales de los ochenta el $50 \%$ de la población colmenareña y cuyos hábitos sociales eran muy distintos en comparación con la tipología de habitantes que vivían en el núcleo histórico. Los datos del parque inmobiliario del plan de 1987 (65\% de vivienda per- 


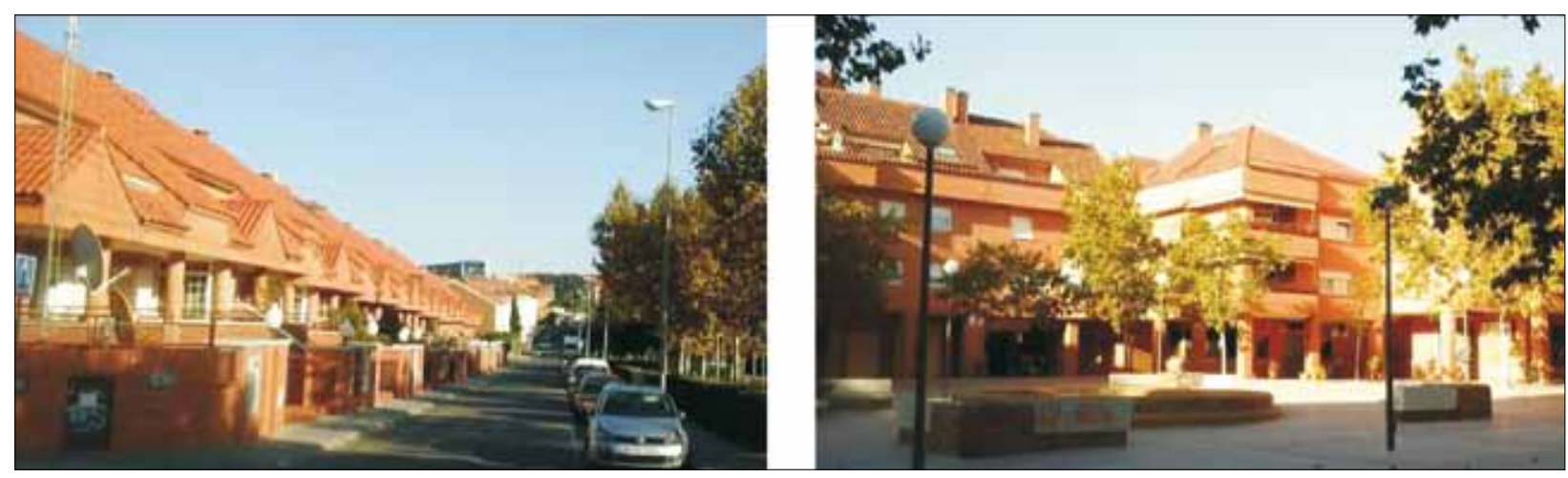

FIg. 6. A la izquierda, viviendas adosadas en el sector de Santa Teresa. Fotografía del autor; a la derecha, vivienda colectiva con comercio en planta baja en el sector de Santa Teresa. Fotografía del autor.

manente, $26 \%$ de segunda vivienda y $12 \%$ de vivienda vacía) y las criticas del mismo documento a la excesiva oferta residencial potencial del plan anterior, que preveía un crecimiento de Colmenar hasta 130.000 habitantes ( sin contar Tres Cantos) y una orientación de dicha oferta hacia Madrid, reflejaban la fuerte primacía de la función residencial. En concreto, dentro del parque de viviendas, el peso de la categoría de la residencia secundaria generaba aún más demanda insatisfecha que contribuía a incrementar el déficit de equipamiento e infraestructuras. Por último, el carácter dependiente de la población, predominantemente menores de 15 años y mayores de 65, con una población activa de apenas el $30 \%$, contribuyó a que Colmenar fuera más un centro de residentes que de trabajadores.

Esta característica de pueblo dormitorio se ha mantenido hasta el período actual. En la memoria del plan general vigente de 2002 (Ayuntamiento de Colmenar Viejo, 2002, pp. 3-6), se subraya la importancia del precio relativamente barato de la vivienda en Colmenar Viejo en comparación con otros núcleos dormitorio de la comunidad de Madrid, como un factor de elección tenido en cuenta por la población madrileña en busca de primera vivienda. Los jóvenes trabajadores, ya mencionados como inmigrantes principales en los ochenta, siguen siendo la categoría sociodemográfica más numerosa entre las atraídas por el parque residencial del municipio. Definido en el mismo documento y con exceso de optimismo como el «centro difusor metropolitano más dinámico en términos demográficos relativos en la corona regional madrileña» en los ochenta, Colmenar Viejo perdió su primacía poblacional y sus aspiraciones metropolitanas en los noventa por la segregación de Tres Cantos (que, según el PGOU, había tenido un crecimiento entre 1987 y 1990 de un
$12 \%$ anual frente a un 5,6\% de todo el municipio). En la figura 2 y cuadro 3 se advierte cómo la segregación de Tres Cantos llegó a afectar al desarrollo demográfico de Colmenar hasta el punto de que, tras su segregación, Tres Cantos llegó a tener incluso más población que Colmenar a comienzos del siglo XXI, si bien la situación se invirtió en los últimos años.

Abundaremos algo más en el asunto demográfico de Colmenar con ayuda del censo de 2001. En este censo se puede distinguir la población residente de la vinculada no residente, siendo también estas cifras representativas de la vocación residencial de Colmenar Viejo. En términos de porcentaje, sobre el total de la carga poblacional soportada por el municipio (residentes y vinculados) el $81,52 \%$ son residentes y los vinculados apenas el $18,48 \%$. Si consideramos que la tasa de vinculación alcanza el $122 \%$, eso significa que hay 22 personas vinculadas por cada 100 residentes, con una clara presencia dominante de estos últimos (cuadro 4).

Más recientemente, los datos de 2008 extraídos del Atlas de la movilidad residencia-trabajo de la Comunidad de Madrid (Comunidad de Madrid, 2010, p. 85) dejan constancia de cómo, con respecto a la relación entre lugar de residencia y lugar de trabajo, en el caso de Colmenar son más los residentes que salen del municipio por motivos de trabajo que los que llegan. En concreto, esta fuente pone de manifiesto la existencia en 2008 de más de 15.000 trabajadores residentes que salen del municipio; sin embargo, tanto los trabajadores residentes que se quedan en el municipio como los que entran se sitúan en una franja de entre 5.000 y 10.000 personas. Esto significa que se trata de un municipio más generador que receptor de viajes vinculados al trabajo, siendo esta característica más típica de municipios con vocación residencial 
CUADRO 7. Sectores de suelo urbanizable programado del plan general de 1987

\begin{tabular}{|c|c|c|c|}
\hline Denominación SUP & Superficie sector & Tipologías y usos previstos & P. parcial aprobado antes de 2002 \\
\hline El Mirador & 59.635 & Res. unifamiliar y colectiva & Sí \\
\hline Sta. Teresa & 300.600 & Res. unifamiliar y colectiva & Sí \\
\hline Fuentecajón & 79.493 & Res. unifamiliar y colectiva & Sí \\
\hline Provicol & 76.046 & Res. unifamiliar y deportivo & Sí \\
\hline El Redondillo & 67.460 & Res. unifamiliar & Sí \\
\hline Moncayo & 71.535 & Res. unifamiliar & Sí \\
\hline Pradotito & 34.600 & Res. unifamiliar y colectiva & Sí \\
\hline El Cerrillo & 25.210 & Res. unifamiliar & No \\
\hline Doble Rotador & 86.135 & Res. unifamiliar y comercio & Sí \\
\hline Olovasio & 49.010 & Res. unifamiliar & Sí \\
\hline Huertas & 57.780 & Res. unifamiliar e industria & No \\
\hline
\end{tabular}

Fuente: PGOU 1987 y 2002.

Cundro 8. Porcentajes de clases de suelo sobre la superficie total municipal, en base al Plan General de 2002

\begin{tabular}{llllll} 
Urbano cons. & $\frac{\text { Urb. no cons. }}{3,8}$ & $\frac{\text { Urbaniz. delim. }}{2,1}$ & $\frac{\text { Urbaniz. no delim. }}{0,6}$ & $\frac{\text { No urbanizable }}{90,5}$ & $\frac{\text { Sist. Gen. y otros }}{2,7}$ \\
\hline
\end{tabular}

Fuente: Ministerio de Fomento.

\section{ATISBOS MUY INCIPIENTES \\ DE LA CONFIGURACIÓN DE COLMENAR VIEJO COMO SUBCENTRO METROPOLITANO}

Colmenar Viejo no es precisamente un municipio que se pueda definir aún como subcentro metropolitano o con características de centralidad secundaria. Sin embargo, es posible encontrar una serie de atisbos que lo sitúan en fase muy incipiente como subcentro, aunque se trata de piezas sueltas y con desarrollo todavía muy germinal hacia la multifuncionalidad.

Entre los proyectos que aportan características de multifuncionalidad merece la pena mencionar las actuaciones que se desarrollaron en Tres Cantos cuando en su tiempo pertenecía todavía al municipio de Colmenar Viejo. El área de Tres Cantos, cuyo municipio se segregó en 1991, representó originalmente un potencial foco de iniciativas orientadas hacia la creación de empresas y actividades. Entre los asentamientos pioneros en su territorio destaca la Zona Industrial Oeste, que fue inaugurada el 22 de octubre de 1987 por los reyes de España y que inicialmente se creó para la implantación de la sede de la multinacional americana Ат\&т. La empresa permaneció en este lugar por un período de más de diez años, hasta que en el año 2000 su edificio fue adquirido por BP Solar. Este proyecto sirvió de acicate para la implantación de otras actividades industriales y empresariales en Tres Cantos, entre las cuales destaca la creación del Parque Tecnológico de Madrid (1985-1987) ${ }^{6}$. Situado en un terreno de más de 28,4 ha, está ocupado por parcelas de tamaño variable entre los 2.500 y $10.000 \mathrm{~m}^{2}$, que en su conjunto ocupan 21,2 ha. Su localización se eligió por su buena accesibilidad y cercanía a Madrid. Está constituido por un centro de empresas, un centro de encuentros y un parque industrial. El primero tiene la función de promover la creación de nuevas empresas de alta tecnología, informática, ingeniería y telecomunicaciones; el segundo se creó para encuentros, reuniones y para albergar la sede de la asociación de empresarios de Tres Cantos; el tercero está ocupado mayoritariamente por empresas de alta tecnología orientadas hacia proyectos de I + D (investiga-

\footnotetext{
${ }^{6}$ El Imade y Tres Cantos, S. A. firmaron unos convenios en 1985 y 1986 y a partir de eso en 1987 se creó la Sociedad Gestora Parque Tecnológico de Tres Cantos, S. A., con capital de 850 millones de pesetas.
} 
CuAdro 9. Capacidad teórica de viviendas en los sectores con vivienda unifamiliar calculada por el plan general

\begin{tabular}{|c|c|c|c|c|c|c|c|}
\hline Sector & $\begin{array}{l}\text { Ha de sector } \\
\text { sin Sist. Gen. }\end{array}$ & Viv./ha & $\begin{array}{c}\text { Núm. teórico } \\
\text { tot. viv. }\end{array}$ & $\begin{array}{l}\text { Núm. teórico } \\
\text { máx. viv. un. }\end{array}$ & $\begin{array}{l}\text { Núm. teórico } \\
\text { máx. viv. col. }\end{array}$ & $\begin{array}{l}\text { Núm. mín. } \\
\text { VPP }\end{array}$ & $\begin{array}{c}\% \text { suelo vPP/ } \\
\text { viv. tot. }\end{array}$ \\
\hline 3. Arroyo Espino & 30 & 30 & 900 & 145 & 755 & 527 & 59 \\
\hline 4. Adelfillas & 29 & 25 & 726 & 244 & 483 & 375 & 52 \\
\hline 5. Amapolas & 13 & 22 & 296 & 297 & 0 & 74 & 25 \\
\hline 6. Alto Eugenio & 21 & 21 & 426 & 427 & 0 & 107 & 25 \\
\hline 7. Cerca Tejera & 20 & 21 & 428 & 428 & & 107 & 25 \\
\hline 8. Navallar & 14 & 31 & 431 & 152 & 280 & 220 & 51 \\
\hline 9. Lavanderas & 47 & 37 & 1737 & 464 & 1274 & 944 & 54 \\
\hline
\end{tabular}

Fuente: PGOU de 2002.

ción más desarrollo). Es cierto que la segregación de Tres Cantos, como se ha explicado en apartados anteriores, favoreció la decadencia de las aspiraciones metropolitanas de Colmenar Viejo.

De hecho, como se explica en la memoria del plan general de 2002 vigente en la actualidad, este municipio «adolece de falta de suelo para servicios terciarios, comprendiendo en estos las oficinas, sedes nacionales o regionales de grandes compañías, empresas relacionadas con la logística de la distribución, empresas de servicio a otras empresas y toda empresa relacionada con el sector de investigación y desarrollo, y con instituciones de enseñanza superior» (Ayuntamiento de Colmenar Viejo, 2002, p. 11). El tipo de actividades terciarias que existe en Colmenar está esencialmente ligado a servicios básicos, la mayoría de los cuales tienen carácter local o comarcal (banca, restauración, abastecimiento de materiales, etc.), pese a que está dotado de una accesibilidad notable tanto a través de la carretera M-607 como mediante el ferrocarril de cercanías.

Con respecto a este último, a principios del siglo XXI se volvió a abrir la estación de Colmenar Viejo, que existía desde que se construyó en 1968 la línea de ferrocarril Madrid-Burgos y quedó sin servicio durante muchos años. Con la duplicación y electrificación de la vía férrea entre Tres Cantos y Colmenar Viejo y la restauración del antiguo edificio de la estación, se volvió a prestar servicio, aunque inicialmente, tras su reapertura en 2002, el tramo de la línea hacia Colmenar tenía la mitad de la frecuencia de trenes respecto a Tres Cantos. La conexión con Madrid mejoró con la inauguración en 2008 de la línea C-4 de cercanías Parla-Colmenar Viejo gracias a la apertura del nuevo túnel entre las estaciones de Atocha y Chamartín.

La competencia a nivel de actividades industriales y empresariales de municipios del norte metropolitano como Tres Cantos, San Sebastián de los Reyes y Alcobendas hizo que en el mismo documento del plan vigente se reconociera que lo único que podría favorecer a Colmenar Viejo respecto a los otros municipios sería el diferencial del precio de suelo, puesto que se entendió la importancia de la demanda y oferta empresarial existente en los alrededores. Las previsiones de este plan para Colmenar con respecto al sector industrial se limitan por lo tanto exclusivamente a una pequeña extensión del suelo urbanizable industrial no programado al sur del municipio, debido a su cercanía a la línea de ferrocarril y ligada a una posible demanda a corto plazo.

Con respecto a otras funciones y usos del suelo, entre las actuaciones recientes destaca la Ciudad Deportiva Juan Antonio Samaranch, un proyecto de gran envergadura que se ha creado en los solares del sector La Estación de Colmenar Viejo ${ }^{7}$, suponiendo una inversión de veinte millones de euros. Situada en proximidad de la estación de trenes de cercanías Renfe, se inauguró en 2010 y está conectada con Madrid capital a través de la citada línea de Cercanías C-4 Colmenar-Parla. Sobre una superficie total de $105.000 \mathrm{~m}^{2}$ se sitúan actividades deportivas de vario tipo (fútbol, tenis, pádel, atletismo, tiro con arco, golf y espacios polideportivos y multifuncionales).

Por último, cabe destacar el proyecto de la Ciudad del Conocimiento, promovido por la Comunidad de Madrid a través del Imade y actualmente paralizado por la crisis económica, que «aspira a invertir profundamente el actual perfil sociolaboral de la localidad orientándola decididamente hacia la economía del conocimiento» (Valenzuela, 2011, p. 223). La actuación ocupará un área de

\footnotetext{
7 En concreto se trata de las parcelas DEP-1 y P-3 del Arunp núm. 2 del sector La Estación del plan general de 2002.
} 
CUADRO 10. Ámbitos de desarrollo del PGOU 2002 con planes parciales y estudios de detalle aprobados

\begin{tabular}{|c|c|c|}
\hline Ámbitos de desarrollo (suP) & Aprob. definitiva P. Parc. & Proy. urbanización \\
\hline PP correspondiente al suP-3, Arroyo Espino & BOCM núm. 18, 22-I-08 & PU восм núm. 40, 17-II-09 \\
\hline PP correspondiente al suP-4 Adelfillas & восм núm. 221, 16-IX-05 & PU восм núm. 139, 13-VI-06 \\
\hline Modificación del pP del sup-4, Adelfillas & Восм supl. al núm. 107, 07-V-07 & \\
\hline PP para el desarrollo del sector núm. 6, Alto Eugenio & воСм núm. 45, 23-II-09 y núm. 48, 26-II-09 & \\
\hline Modificación del PP correspondiente al sector núm. 6, Alto & & \\
\hline Eugenio & BOCM núm. 99, 27-IV-10 & \\
\hline PP correspondiente al sector núm. 7, Cerca Tejera, del PGOU & BOCM núm. 72, 25-III-10 & \\
\hline PP correspondiente al suP- 8 Navallar & восм núm. 265, 07-XI-05 & \\
\hline $\begin{array}{l}\text { Modificación del PP de iniciativa particular correspondiente al } \\
\text { suP- } 8 \text { Navallar }\end{array}$ & восM núm. 6, 08-I-08 & \\
\hline $\begin{array}{c}\text { Unidades de ejecución } \\
\text { (desarrollos en suelo urbano no consolidado) }\end{array}$ & Aprobación definitiva E. det. & Proy. urbanización \\
\hline ED de la UE-40/1 La Pesadilla & BOCM núm. 67, 21-III-05 & \\
\hline ED de la UE-20/1 San Crispín-Los Nardos & восм núm. 172, 21-VII-05 & PU BOCM núm. 312, 31-XII-05 \\
\hline ED de la UE-11/7 Diprife & восм núm. 45, 23-II-04 & PU BOCM núm. 120, 21-V-04 \\
\hline ED de la UE-13/1 Sierra Nevada & Восм supl. al núm. 177, 27-VII-04 & \\
\hline Resto de figuras & Aprobación definitiva & Proy. urbanización \\
\hline Área de reparto 2, sector 1, La Estación & & PU BOCM núm. 254, 25-X-04 \\
\hline PE de la manzana DSM-1 del Arunp N2, sector 1, La Estación & BOCM núm. 27, 01-II-07 & \\
\hline $\begin{array}{l}\text { Plan de sectorización, con ordenación pormenorizada del sector } \\
\text { La Estación del PGOU de Colmenar Viejo }\end{array}$ & Восм núm. 40, 17-II-04 & \\
\hline Proyecto de reparcelación voluntaria en el AOE-37 Pozanco & Восм núm. 58, 10-III-05 & \\
\hline
\end{tabular}

Fuentes: PGOU 2002, восм, Colegio Oficial de Arquitectos de Madrid.

siete millones de metros cuadrados y en sus previsiones debería haber generado alrededor de 25.000 empleos cualificados, integrándose en la red de parques tecnológicos de la Comunidad de Madrid. El proyecto, sin embargo, no ha pasado hasta ahora de una formulación muy embrionaria.

\section{EVOLUCIÓN HISTÓRICA Y ANÁLISIS MORFOLÓGICO DEL HÁBITAT UNIFAMILIAR EN COLMENAR VIEJO}

Para comprender la configuración del hábitat residencial unifamiliar en Colmenar Viejo parece oportuno realizar una macro-subdivisión del territorio municipal en ámbitos morfológicos. A tal propósito el documento del PAI Norte de 1979 (Coplaco, 1979) y el resumen del
PAI de Colmenar de 1981 (Coplaco, 1981) delimitan una serie de áreas cuyo desarrollo ha derivado de un proceso de ocupación históricamente distinto: el casco se ha dividido entre el núcleo más interior constituido por el casco antiguo, tradicionalmente el lugar de concentración de funciones urbanas y administrativas, y el casco urbano, con trazado viario de origen rural y parcelación irregular, a lo largo de los años sometido a procesos de alteración de la edificación original; las áreas de ensanche, constituidas por las denominadas como «colonias integradas en el casco», que aparecen en continuidad con su trama viaria y por algunas zonas de bloques colectivos adyacentes; las urbanizaciones periféricas, que pueden estar en proximidad del casco (llamadas por eso en el documento «perimetrales», incluyendo tanto colonias de viviendas adosadas como desarrollos del tipo ciudad jardín) o aisladas de él, siendo estas ultimas las de mejor calidad y ni- 


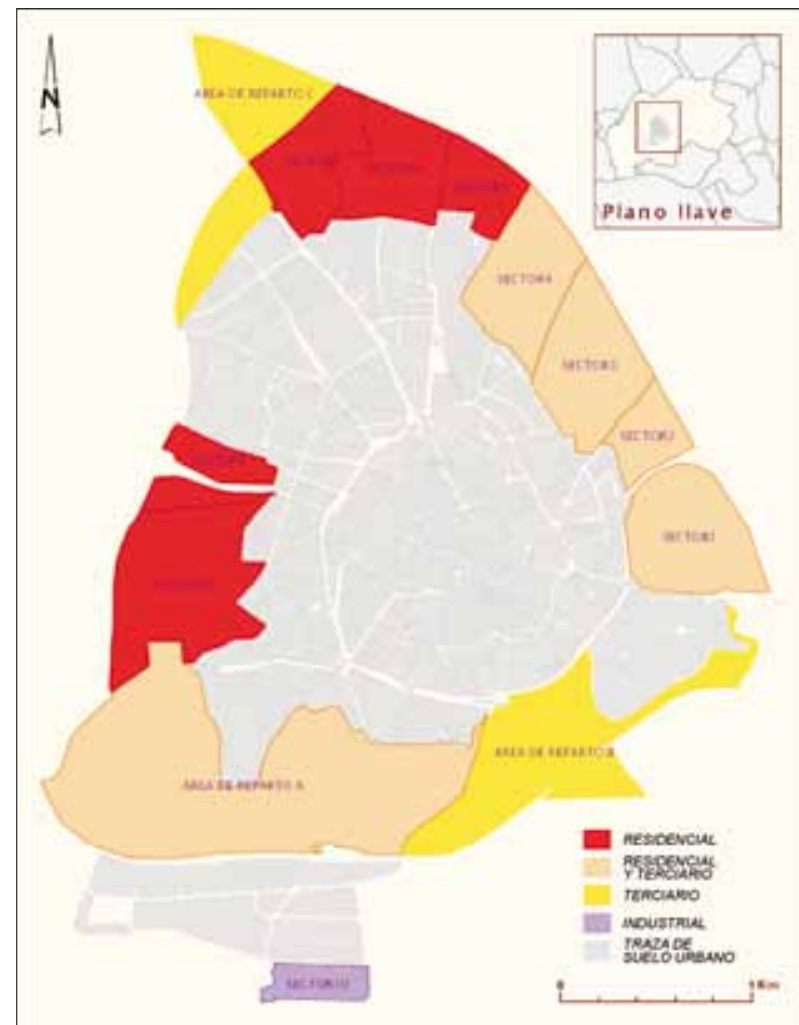

FIG. 7. Ámbitos de desarrollo del PGOU de 2002. Fuente: Comunidad de Madrid (2006)

vel socioeconómico. Esta subdivisión puede reflejarse en la del Plan General de Ordenación Urbana (PGOU) vigente de 2002 aunque con denominaciones distintas.

Esencialmente el plan general vigente establece para las zonas consolidadas del núcleo central de Colmenar ocho áreas de ordenanza (AO), de las cuales las primeras seis son las más significativas para establecer una correspondencia con la anterior clasificación del PAI y localizarlas en la figura 4: AO-1 Casco Antiguo, AO-2 Ensanche del Oeste, AO-3 Ensanche del Este, AO-4 Colonias del Norte, AO-5 Colonias del Sur, AO-6 Colonias del Este. Esencialmente el casco se agrupa en una única área, las colonias integradas en el casco se incluyen en las denominaciones Ensanche del Oeste y Ensanche del Este, mientras que las colonias del norte, sur y este son las anteriormente definidas como «urbanizaciones periféricas perimetrales». Las áreas AO-7 y AO-8 se refieren a una pequeña área industrial y a otra dotacional cuyo contenido no parece importante profundizar en este apartado.

En la figura 4 se representan las subdivisiones de estas AO en subáreas, denominadas en función de los desarrollos o de las urbanizaciones en ellas contenidas; así que, para identificar muchos de los asentamientos que se mencionarán más adelante en el texto, tendremos que hacer referencia a esta figura.

Para estudiar las grandes piezas que han configurado el desarrollo de la vivienda unifamiliar en Colmenar, resulta significativo incluirlas en las fases históricas de evolución urbanística de Colmenar, con el fin de analizar con mayor detalle cada pieza y situarla bajo un punto de vista espacio-temporal.

\section{EL PERÍODO ANTERIOR AL PLAN GENERAL DE 1969: PARCELACIONES Y URBANIZACIONES}

Por lo que atañe al período anterior a la aprobación del primer plan general municipal de 1969 , de la zonificación en áreas de ordenanza anteriormente enunciada merecen especial atención las denominadas como «colonias integradas en el casco». Situadas en el ensanche, bordean el casco en su parte oeste y este y su viario se ha diseñado en continuidad con el trazado del núcleo más antiguo sobre los antiguos caminos que conducían hacia los pastos y campos de labor. La mayoría de estas actuaciones existían ya antes del 1969, algunas creadas en los años cincuenta y otras entre 1965 y 1975. Tenían como tipología residencial única la vivienda unifamiliar y estaban originalmente destinadas a clases medias-bajas. $\mathrm{Su}$ proceso de promoción, de carácter unitario, preveía la adquisición por parte de las inmobiliarias de las parcelas agrarias, la ejecución de una parcelación de entre 75 y $150 \mathrm{~m}^{2}$, la construcción de viviendas unifamiliares idénticas entre ellas y la posterior enajenación de viviendas y suelo. La calidad de las viviendas y el tamaño reducido se pueden considerar una demostración de que el destinatario de estas viviendas era la clase obrera (Coplaco, 1979, p. 100). Dentro de esta categoría podemos mencionar la colonia La Paz (o Labradores), concebida como «actuación de Regiones Devastadas, para albergue de labradores y obreros», cuya construcción se terminó en el año $1957^{8}$.

Entre finales de los años cincuenta y comienzo de los sesenta se construyen las definidas por el PAI de Colmenar como «urbanizaciones periféricas perimetrales» al casco y representadas en la Fig. 4 con la denominación de AO4, AO-5 y AO-6. Estas urbanizaciones están ubicadas en el extrarradio del núcleo en dirección norte (Los Remedios,

\footnotetext{
8 Fuente de la fecha y de la información: documento resumen del PAI de Colmenar (Coplaco, 1981).
} 


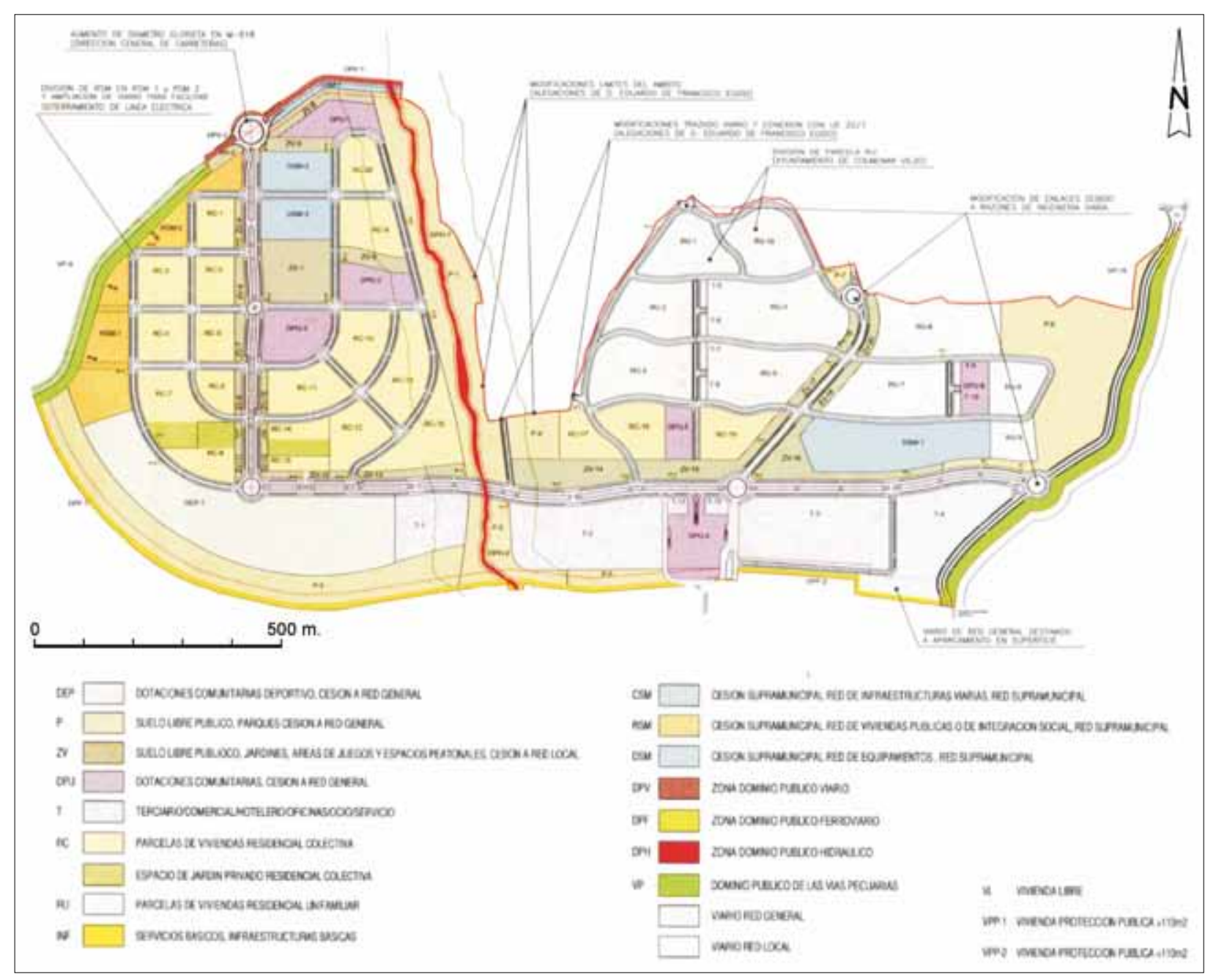

FIG. 8. Zonificación del sector de La Estación. Fuente: Plan de Sectorización del Sector La Estación.

Las Torres, Dos Castillas, todas incluidas en el AO-4 y Las Vegas, en el AO-6) y sur (San Crispín, La Magdalena, incluidas en el AO-5). Dentro de este grupo sería más correcto definir por el origen de los asentamientos Los Remedios y La Magdalena como parcelaciones y las demás como urbanizaciones en el sentido más estricto. El destinatario es de un nivel económico levemente más alto respecto a las colonias situadas en el ensanche del casco, pese a que puede haber casos de viviendas más antiguas y más modestas. De hecho, se puede establecer una diferencia morfológica dentro del mismo grupo de urbanizaciones y colonias periféricas del extrarradio: por un lado los asentamientos de viviendas unifamiliares de entre finales de los cincuenta y comienzos de los años sesenta se caracterizaban por la presencia de viviendas adosadas en hilera o pareadas sobre parcelas mínimas de $250 \mathrm{~m}^{2}$ (por ejemplo Los Remedios, cuya construcción se terminó en $1959^{9}$, o Dos Castillas, de 1960) sobre una trama viaria ortogonal y con calles originalmente no pavimentadas; por otro, los asentamientos posteriores, sobre todo los de la segunda mitad de los años sesenta, estaban constituidos por viviendas aisladas construidas sobre parcelas de entre 500 y $1.000 \mathrm{~m}^{2}$ (como en el caso de Las Vegas, al noreste, y San Crispín, al sur) sobre un trazado viario variable de ortogonal a sinuoso (Coplaco, 1981, pp. 20-27). Muchas de las viviendas incluidas en esta categoría estuvieron en su origen destinadas a residencias secundarias para veraneantes madrileños de nivel socioeconómico medio-bajo. Las denominadas como

\footnotetext{
9 Fuente de la fecha: documento resumen del PaI de Colmenar (Coplaco, 1981).
} 

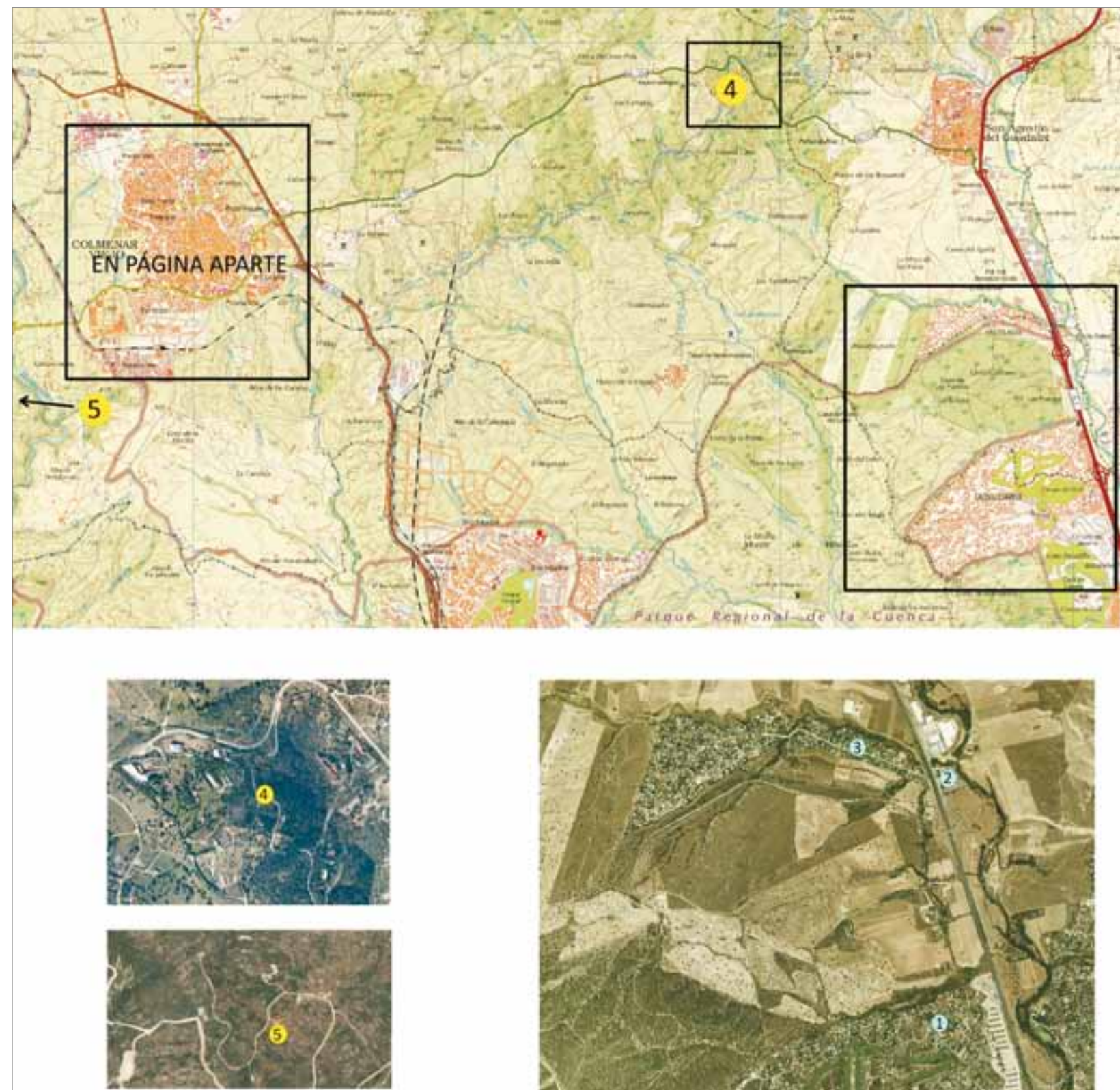

Urbanizaciones aisladas del casco anteriores al Plan General de 1969

\section{1.- Ciudalcampo \\ 2.- Punta Galea \\ 3.- Valdelagua}

Desarrollos ilegales posteriores al Plan General de 1969

\section{4.- Los Chortales}

5.- Los Pajarejos

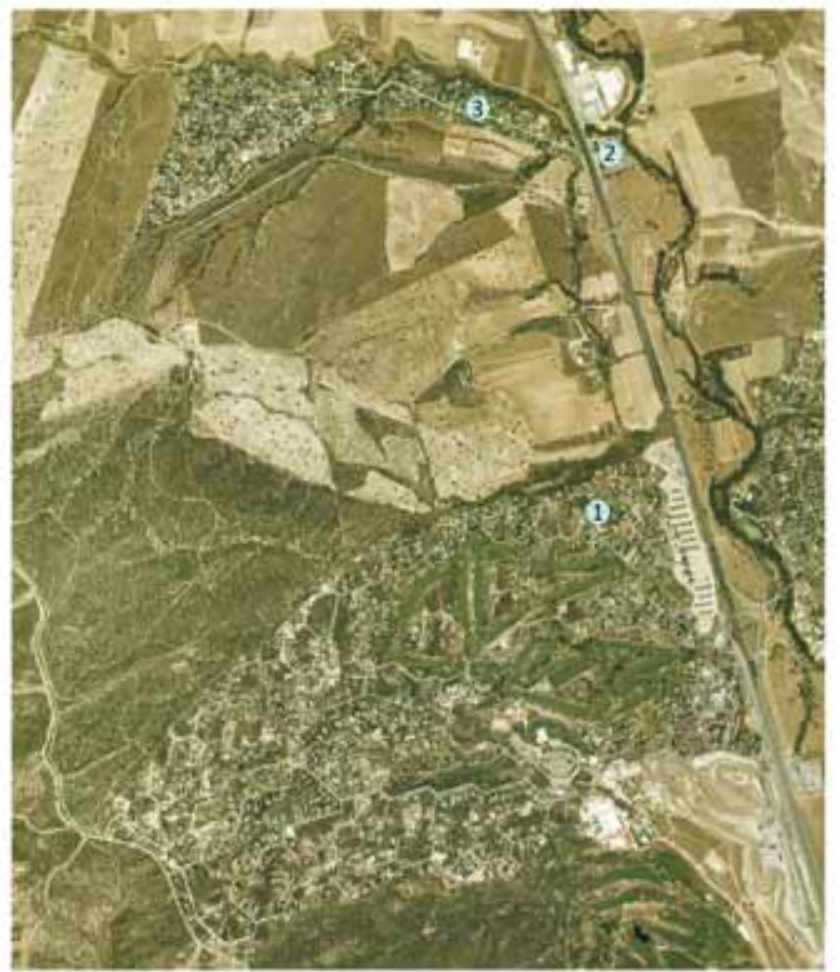

Fig. 9. A la izquierda, desarrollos de vivienda unifamiliar en Colmenar Viejo (casco). Fuente: Planea, visor cartográfico de la Comunidad de Madrid Elaboración propia con la colaboración de Juan de la Puente; a la derecha, desarrollos de vivienda unifamiliar en Colmenar Viejo (periferia). Fuente: Planea, visor cartográfico de la Comunidad de Madrid. Elaboración propia con la colaboración de Juan de la Puente. 


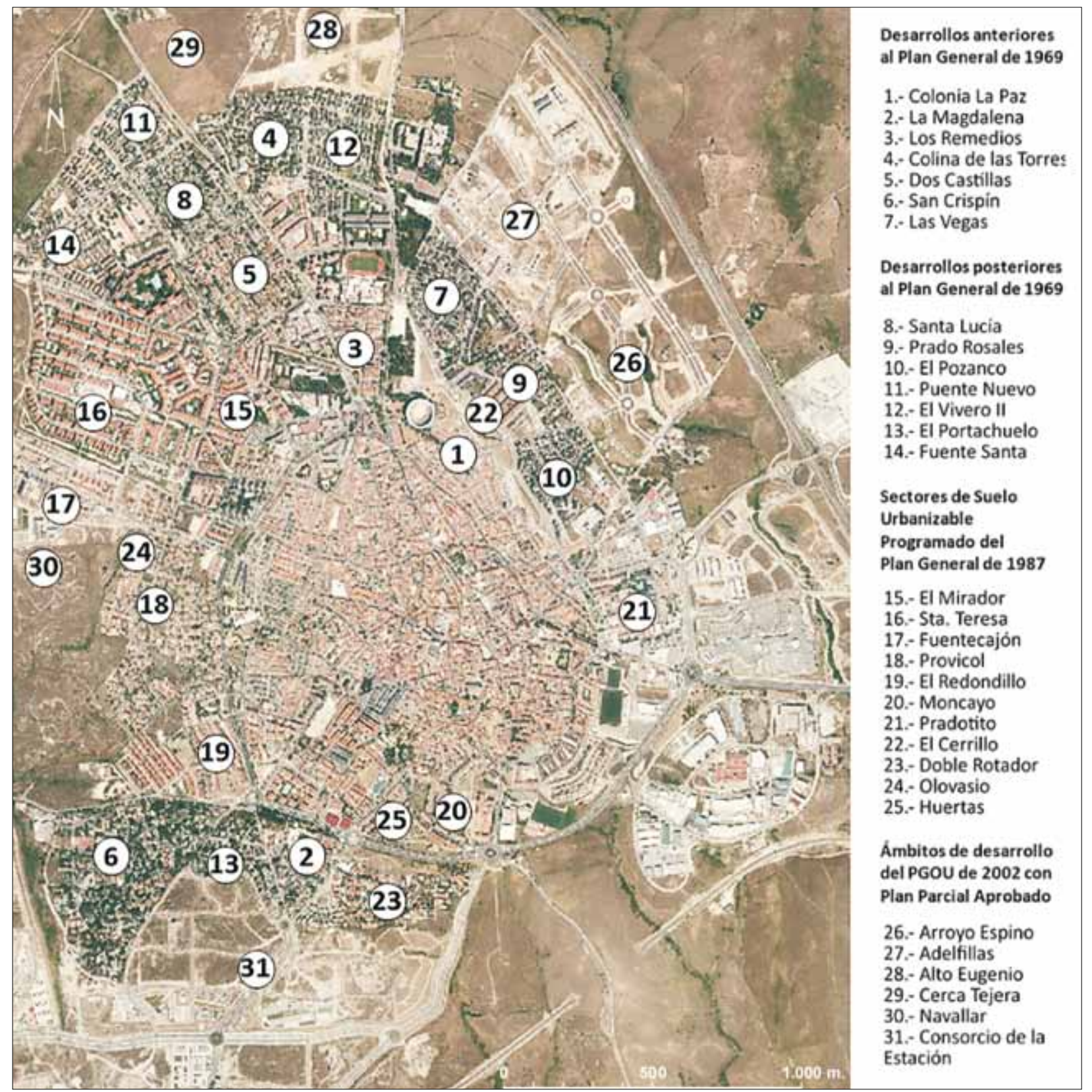

«urbanizaciones periféricas aisladas», que no tienen relación directa con el núcleo histórico si no fuera por el hecho de que pertenecen al mismo término municipal, tienen un carácter más metropolitano que local. Las tres más importantes (Soto de Viñuelas, Ciudalcampo y Valdelagua) se remontan al año 1968 y tienen como característica peculiar la de compartir parte de su superficie con otros municipios (Ciudalcampo y Valdelagua) o de haber sido integradas posteriormente en otro término municipal (Soto de Viñuelas en Tres Cantos después de su segregación). Soto de Viñuelas estaba ubicado en el antiguo límite sur del término municipal de Colmenar, hoy pertenece a Tres Cantos, es accesible desde la M-607 y se caracteriza por un trazado viario elemental organizado en torno a un vial principal, con parcelas mínimas de 1.500 $\mathrm{m}^{2}$. Valdelagua, situada en el corredor de la A-1 a caballo 
del límite municipal con San Agustín de Guadalix, tiene características de urbanización de alto nivel con parcelas de gran tamaño (mínimo de $2.000 \mathrm{~m}^{2}$ ) y viviendas de calidad elevada; sólo pertenece al municipio de Colmenar su porción más pequeña. En la misma zona, al otro lado de la A-1, surgió Punta Galea, pequeño desarrollo de once hotelitos pareados legalizado en 1968. Por último, la urbanización Ciudalcampo, que limita con y está en parte situada en el término municipal de San Sebastián de los Reyes, en el mismo corredor de la autovía Madrid-Burgos, fue desarrollada sobre la finca La Pesadilla y promovida por Ciudalcampo, S. A. ${ }^{10}$ Se puede definir como una urbanización de alto standing, localizada en un encinar, con tamaños de parcelas de entre 2.500 y 5.000 $\mathrm{m}^{2}$ y una malla viaria de diseño hexagonal. Estas actuaciones se encuentran en un área recreacional suburbana con función de esparcimiento en que tenían cierto papel catalizador las actividades deportivas y los clubes sociales. Destacaban en la zona entre la M-607 y la A-1 la presencia del complejo RACE y del campo de golf anexo al circuito automovilístico en el mismo monte La Pesadilla donde se asentó la urbanización Ciudalcampo. En la carretera de Colmenar surgieron la instalaciones del Club Soto de Viñuelas (club de campo) y, más cercanas a Madrid, las del Club de Tiro Canto Blanco (Valenzuela, 1977, p. 399).

\section{EL DESARROLLO DE LA VIVIENDA UNIFAMILIAR AFECTADO POR EL PRIMER PLAN GENERAL (1969) Y EL PLAN GENERAL DE 1987}

En el año 1969 se aprobó el primer plan general de Colmenar Viejo. Este plan pretendía estructurar un núcleo con trazado viario de origen rural y manzanas irregulares suponiendo un incremento demográfico de hasta cien mil habitantes en lo que entonces fue definido como «suelo de reserva urbana», una definición de suelo urbanizable anterior a la ley del Suelo de 1975. Además, incluía el proyecto de creación de Tres Cantos, generando todas las contradicciones entre aspiraciones comarcales y metropolitanas apuntadas anteriormente. El plan diseñaba un esquema urbanístico radiocéntrico alrededor del casco y ensanche proponiendo una primera corona de bloques de

\footnotetext{
10 En la página web de la urbanización, <www.ciudalcampo.org $>$, se afirma que «el 10 de enero de 1968, la Coplaco, lo que hoy en día es la Consejería de Ordenación del Territorio, aprobó el plan parcial de Pesadilla, promovido conjuntamente por el RACE y Ciudalcampo, S. A., según proyecto redactado por el arquitecto D. Antonio Perpiñá Sebriá».
}

CuAdro 11. Bienes inmuebles unifamiliares por décadas de construcción

\begin{tabular}{|c|c|c|c|}
\hline Período & $\begin{array}{l}\text { Sup. construida media } \\
\text { de bien inmueble }\left(\mathrm{m}^{2}\right)\end{array}$ & $\begin{array}{c}\text { Parcela } \\
\text { media }\left(\mathrm{m}^{2}\right)\end{array}$ & $\begin{array}{l}\text { Núm. } \\
\text { parcelas }\end{array}$ \\
\hline $1951-1960$ & 154,58 & 293,20 & 597 \\
\hline $1961-1970$ & 171,37 & 171,37 & 1.343 \\
\hline $1971-1980$ & 272,73 & 494,94 & 463 \\
\hline $1981-1990$ & 267,56 & 499,17 & 943 \\
\hline $1991-2000$ & 234,31 & 345,91 & 1.351 \\
\hline $2001-2011$ & 283,51 & 326,56 & 1.219 \\
\hline
\end{tabular}

Fuente: catastro. Elaboración propia.

vivienda colectiva y una segunda de actuaciones del tipo ciudad jardín. Tenía fuerte caracterización residencial toda la zona oeste y noroeste dejando al sur las industrias y las áreas pre-existentes de unifamiliares. Este plan general preveía una serie de planes parciales muchos de los cuales se quedaron sin desarrollar, aunque el plan siguiente de 1987 tuvo que recoger alrededor de 25 planes parciales que se habían desarrollado de forma desordenada, sin que hubiese conexión entre ellos. Como se explica en el plan de 1987 en referencia al plan de 1969,

[...] el desarrollo del plan se preveía en base a planes parciales para los que no se establecía la unidad mínima del mismo, ni se programaba el desarrollo coordinado del suelo de reserva urbana. Tan sólo se exigía que los planes parciales tuvieran zonas verdes en proporción no inferior al $10 \%$ de la superficie ordenada y reserva de suelo escolar proporcional a las necesidades de la población. El sistema de actuación para la práctica totalidad era la cesión de viales. (Ayuntamiento de Colmenar Viejo, 1987, p. 49)

Así, posteriormente a la aprobación del plan de 1969 se implantaron unas urbanizaciones de viviendas unifamiliares que llenaron alrededor del casco los huecos dejados por las antiguas y ampliaron la cantidad de suelo urbanizado. El proceso de desarrollo de estos asentamientos se basaba en la adquisición de suelo por parte de las inmobiliarias y a la posterior reparcelación según los usos que se iban a implantar.

Los planes parciales de los años setenta, que aparecen en el cuadro 6 , se pueden casi todos enmarcar perfectamente en la subdivisión del territorio municipal anteriormente propuesta. Algunos de ellos se ejecutaron varios años después de la aprobación del plan. En el plan general vigente de 2002 se incluye Santa Lucía, El Vivero II y Puente Nuevo en el grupo de las Colonias del Norte, El Portachuelo en las Colonias del Sur, pudién- 
CUADRO 12. Ejemplos extrapolables a municipios limítrofes

\begin{tabular}{|lllll|}
\hline \multicolumn{1}{c}{ Tipo de actuación } & Ejemplos en Colmenar Viejo & & \multicolumn{1}{c}{ Ejemplos en municipios de los alrededores } \\
\cline { 1 - 1 } $\begin{array}{l}\text { Urbanizaciones periféricas perimetrales } \\
\text { (décadas 1980-1990) de adosados alrededor de } \\
\text { casco antiguo de origen rural }\end{array}$ & $\begin{array}{l}\text { El Redondillo, Prado Tito, El } \\
\text { Cerrillo, Santa Teresa }\end{array}$ & & $\begin{array}{l}\text { San Agustín del Guadalix (pequeñas urbanizaciones } \\
\text { perimetrales al casco en dirección norte y oeste); } \\
\text { Algete (sectores perimetrales al casco) }\end{array}$ \\
$\begin{array}{l}\text { Urbanizaciones periféricas perimetrales } \\
\text { (décadas 1980-1990) de pareados } \\
\text { alrededor de casco antiguo de origen rural }\end{array}$ & Provicol, Fuentecajón & & $\begin{array}{l}\text { San Agustín del Guadalix (Las Fuentes y unidad de } \\
\text { actuación 14) }\end{array}$ \\
$\begin{array}{l}\text { Urbanizaciones de alto standing (años sesenta) } \\
\text { Ciudalcampo, Valdelagua }\end{array}$ & & $\begin{array}{l}\text { San Sebastián de los Reyes (Ciudalcampo, Fuente } \\
\text { del Fresno, Club de Campo); San Agustín de } \\
\text { Guadalix (Valdelagua); Algete (Santo Domingo y } \\
\text { Valderrey); Tres Cantos (Soto de Viñuelas) }\end{array}$ \\
$\begin{array}{l}\text { Urbanizaciones ilegales aisladas en suelo } \\
\text { rústico para segundas residencias de clases } \\
\text { medias-bajas y con trazado viario desordenado }\end{array}$ & $\begin{array}{l}\text { Los Pajarejos (Los Chortales } \\
\text { no se incluye al estar destinada } \\
\text { a viviendas para clases altas) }\end{array}$ & Miraflores de la Sierra (Las Huelgas) \\
\hline
\end{tabular}

Fuente: Elaboración propia.

CUADRo 13. Ejemplos extrapolables a municipios del mismo eje temático

\begin{tabular}{|c|c|c|}
\hline Tipo de actuación & Ejemplos en Colmenar Viejo & $\begin{array}{l}\text { Ejemplos en otro municipios híbridos entre } \\
\text { cabecera comarcal y pueblo dormitorio }\end{array}$ \\
\hline $\begin{array}{l}\text { Urbanizaciones periféricas perimetrales } \\
\text { (décadas 1980-1990) de adosados o pareados } \\
\text { alrededor de casco antiguo de origen rural }\end{array}$ & $\begin{array}{l}\text { El Redondillo, Prado Tito, El Cerrillo, } \\
\text { Santa Teresa, Provicol, Fuentecajón }\end{array}$ & $\begin{array}{l}\text { Navalcarnero (El Señorío, Los Manzanos, } \\
\text { El Olivar) }\end{array}$ \\
\hline $\begin{array}{l}\text { Vivienda unifamiliar en plan parcial reciente } \\
\text { multifuncional y con variedad tipológica } \\
\text { ligado a la accesibilidad por ferrocarril }\end{array}$ & Barrio de La Estación & $\begin{array}{l}\text { Navalcarnero (La Dehesa); Valdemoro (UDE } \\
\text { oeste-norte) }\end{array}$ \\
\hline
\end{tabular}

Fuente: Elaboración propia.

dose incluir ambas categorías por su localización en la denominación del PAI Urbanizaciones Periféricas Perimetrales. También pertenecerían a esta misma categoría del PAi por su localización El Olovasio, Santa Teresa de Ávila, Fuente del Cajón, Fuente Santa, Prado Rosales, El Pozanco y El Redondillo. Las parcelas mínimas varían entre tamaños que, en relación con la tipología unifamiliar, se pueden considerar pequeños $\left(120-300 \mathrm{~m}^{2}\right)$ y medios $\left(500-750 \mathrm{~m}^{2}\right)$.

De las urbanizaciones aisladas del casco, hay que mencionar El Madroñal del Guadalix, concebido como una ampliación de la urbanización Valdelagua, a pesar de que fue clasificada como suelo no urbanizable en 1987 al no haberse completado ni la urbanización. Un caso aparte constituyen los núcleos de Los Chortales y Los Pajarejos, dos agrupaciones ilegales de viviendas unifamiliares en parcelas de 2,5 ha asentadas sobre suelo rústico, que nacieron como urbanizaciones de carácter ilegal alrededor de los años setenta para segundas residencias de alto nivel en el primer caso y de nivel mucho más bajo en el segundo.

La identificación de la fecha de construcción de estos asentamientos no ha resultado fácil puesto que, como se recuerda en la memoria del plan general de 2002, el plan anterior, de 1987, tuvo que «recoger más de 25 planes parciales que de forma descoordinada habían ido desarrollando aisladamente el núcleo urbano (Ayuntamiento de Colmenar Viejo, 2002, p. 4). El Plan de 1987, por lo tanto, intentó configurar la estructura externa global del suelo urbanizable pese a que la estructura interna de los sectores de los planes parciales preexistentes no fuese muy adecuada. Un caso especial es el casco antiguo, afectado por el proyecto de modificación de suelo urbano de 1981, que intentó reducir la densidad global pero permitió una fuerte alteración de las edificaciones preexistentes destruyendo parte de su trama urbana.

Un buen ejemplo de áreas con plan parcial aprobado anteriormente a 1987 y no consolidadas son las áreas de 


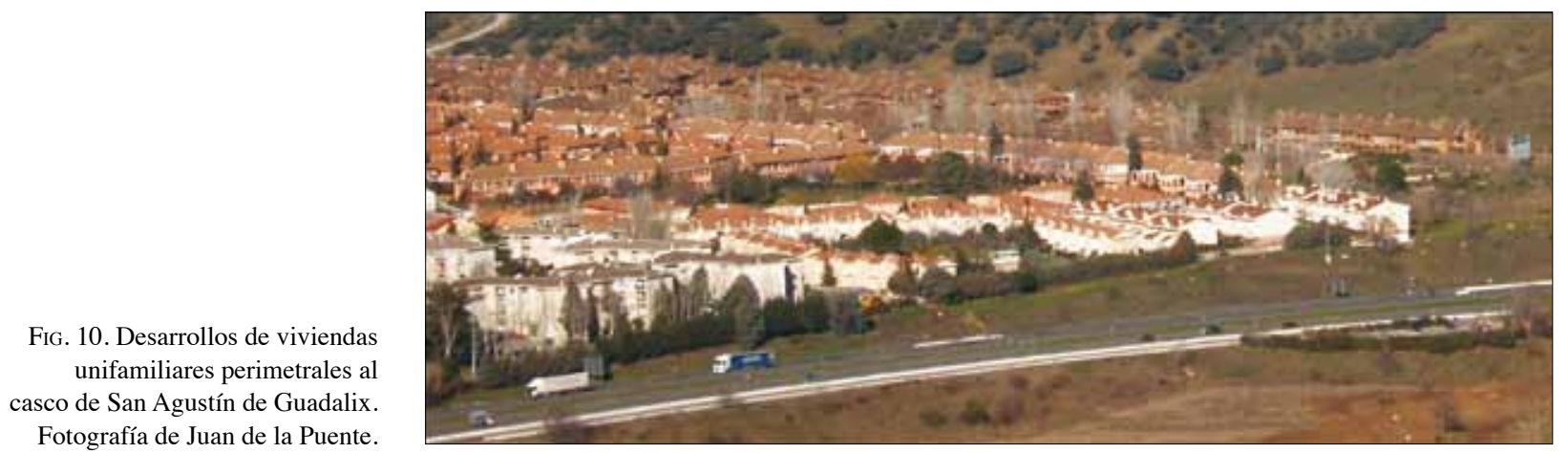

ordenación especial (AE) del plan de 1987, categoría que, además de dichos planes parciales, incluía en su tiempo también vacíos urbanos a desarrollar o actuaciones de reordenación sistemática. Estas áreas tenían un nivel de ordenación muy detallado en el mismo plan general, al estar ya semiconsolidadas. Destaca entre estas AE la presencia de los previamente mencionados ámbitos de Fuentesanta, Prado Rosales y El Pozanco, cuyos planes parciales originales se remontaban a los años setenta. También merece la pena subrayar que Santa Teresa, Doble Rotador, Fuenecajón, El Olovasio y El Redondillo se clasifican en el plan general de 1987 como suelo urbanizable programado (SUP) a pesar de tener ya sus planes parciales aprobados, demostrando así la lentitud de la urbanización y ejecución de ciertos asentamientos ya previstos por el plan de 1969. De hecho, los sectores de suelo urbanizable programado del plan de 1987, cuya denominación queda reflejada en el cuadro 7 , merecen especial consideración puesto que tenían todos al menos una parte de su superficie destinada a la vivienda unifamiliar. Su localización se cartografiará más adelante. Entre ellos destaca el barrio de Santa Teresa, por su carácter multitipológico y multifuncional.

\section{DESARROLLOS AFECTADOS POR EL PLANEAMIENTO VIGENTE}

El plan de ordenación urbana vigente se remonta al año de 2002. En una primera aproximación, es de destacar la influencia que ha tenido como barrera a la expansión del municipio afectando al suelo no urbanizable la aprobación, en consonancia con la ley autonómica del parque regional de la Cuenca Alta del Manzanares (plan rector de uso y gestión, publicado en el $B O E$ de 31 de julio de 1987) que ha consolidado la preminencia de los terrenos no urbanizables en el municipio de Colmenar, que hoy en día ocupan más del noventa por ciento del territorio municipal (cuadro 8), según el Sistema de Información Urbanística (sIU) del Ministerio de Fomento.

Por lo que concierne al suelo urbano, el plan vigente ha mantenido muchas de las áreas de ordenación del plan anterior diferenciando las zonas consolidadas (áreas de ordenanza) de las que han tenido un proceso de consolidación reciente o que todavía no se ha concluido. Dentro de este segundo grupo se diferencian las áreas de ordenación especial (AE) provenientes del plan del 1987 que se han utilizado para los ámbitos con proceso de consolidación reciente, es decir ocurrido entre el plan anterior y el vigente y las unidades de ejecución (UE), en suelo urbano no consolidado, que aún carecen de urbanización o equidistribución ${ }^{11}$. Para nuestro estudio resultan de mayor interés las primeras, puesto que, por tener un mayor grado de consolidación en comparación con el plan general de 1987, permiten registrar la evolución de los procesos edificatorios ocurridos entre el plan de 1987 y el de 2002. De forma pormenorizada, se han cartografiado dichos desarrollos, pues se trata, como se puede ver, de unidades de tamaño mediano-pequeño que no merece la pena estudiar de forma pormenorizada.

Por lo que respecta a las áreas de planeamiento incorporado, se trata en su mayoría de antiguos sectores clasificados como suelo urbanizable programado en el plan de 1987 que se han desarrollado completamente pasando a tener condición de suelo urbano. Se hace referencia a esta clasificación de carácter meramente técnico, sobre

11 Existen también otras dos denominaciones que no resultan muy significativas para este estudio en concreto o que no aportan nada nuevo respecto a las consideraciones ya anteriormente expresadas: la denominación «polígonos de actuación» (PA) se utiliza para áreas con condiciones específicas de actuación mientras que las urbanizaciones fuera del núcleo se clasifican como «urbanizaciones dispersas» (UD). 
todo por la importancia que tienen las AE y las APIS n el estudio histórico de la vivienda unifamiliar en Colmenar Viejo. En este último caso se están considerando sectores que en 1987, pese a que muchos de ellos tenían un plan parcial anteriormente aprobado, no se habían llegado ni a urbanizar ni a edificar en el año de redacción del plan general anterior; por eso se mantuvo su condición de Suelo Urbanizable hasta 2002.

Respecto al suelo urbanizable, el Plan vigente prevé una serie de ámbitos de desarrollos (diez sectores y tres áreas de reparto). El cuadro 9 refleja siete de los diez sectores, que son los únicos donde se prevé la inclusión de la vivienda unifamiliar, destacando los sectores 6 y 7 por su condición mayoritaria. Merece la pena resaltar también la presencia de vivienda de protección pública prevista en dichos sectores con porcentajes que varían entre el $25 \%$ y el $59 \%$. La mayoría de los sectores proponen como usos característicos una mezcla de residencial y terciario.

Mediante la información publicada en el Boletín Oficial de la Comunidad de Madrid (восм) se ha podido verificar la aprobación de los planes parciales de los ámbitos de suelo urbanizable programado del plan general vigente, así como de algunos estudios de detalle relativos a unidades de ejecución en suelo urbano no consolidado y de los correspondientes proyectos de urbanización. En la información contenida en el cuadro 10 resulta que de los siete sectores de suelo urbanizable programado con vivienda unifamiliar prevista, cinco han obtenido la aprobación de su plan parcial y dos de su proyecto de urbanización.

Este mismo cuadro hace también referencia al área de reparto 2 del suelo urbanizable no programado. En esta área de reparto se ha promovido el proyecto del barrio de La Estación, cuyo desarrollo, gestión y ejecución se han llevado a cabo gracias a la creación de un Consorcio Urbanístico por parte del Ayuntamiento de Colmenar y de la Comunidad de Madrid. El proyecto de urbanización de este barrio fue aprobado en 2004 y las obras empezaron en 2005. Asentado sobre una superficie de 1.433.159 $\mathrm{m}^{2}$ el barrio se compone de 3.115 viviendas (con una densidad de 21,75 viviendas por hectárea), de las cuales 1.537 son libres (710 unifamiliares y 827 colectivas) y 1.578 de protección pública, de entre ellas 500 en régimen de alquiler con opción a compra para jóvenes colmenareños ${ }^{12}$. Además del suelo residencial, destacan los

\footnotetext{
12 La información proviene de un reportaje del Ayuntamiento de Colmenar publicado en su página web: <www.colmenarviejo.com/castellano/Reportajes/08 59E25D439B4475BBA9B4D3CAFB6152.asp>.
}

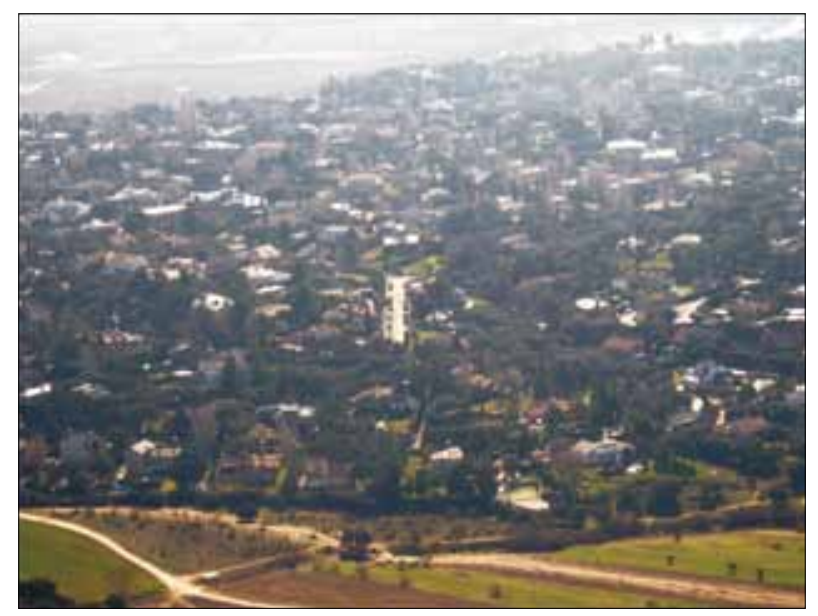

FIG. 11. Urbanización Santo Domingo (Algete). Fotografía de Juan de la Puente.

$315.418,51 \mathrm{~m}^{2}$ de zonas verdes y espacios libres, la presencia de áreas para actividades terciarias y una amplia zona deportiva de más de 80.000 metros cuadrados. Se han querido mencionar algunos detalles de este último proyecto por su envergadura, por ser relativamente reciente y por representar un ejemplo de desarrollo residencial extremamente ligado, por su localización al sur del término municipal, a la accesibilidad por medio del ferrocarril de cercanías.

Del estudio histórico sobre la vivienda unifamiliar en Colmenar realizado con ayuda de fuentes de origen diferente, resulta que el sector de la edificación residencial en Colmenar se ha recuperado a partir de los años noventa, si bien esta consideración está ligada a la observación hecha en apartados anteriores sobre el escaso desarrollo de muchos planes parciales de los años setenta y al mayor desarrollo ocurrido posteriormente a la aprobación del plan general de 1987. Con el apoyo de los datos catastrales relativos a los bienes inmuebles unifamiliares en Colmenar presentados en el cuadro 11, se puede resaltar la existencia de fases de auge y decadencia de la construcción en el municipio.

Observando el número de parcelas edificadas por época de construcción, destaca en este cuadro cómo ha habido una gran fase de desarrollo en la década de los sesenta seguida de un periodo de relajación del sector de la construcción en los años setenta y ochenta del siglo pasado. En los años noventa y en la primera década del siglo XXI el sector se recupera gracias a los proyectos ligados a los desarrollos de los últimos dos planes generales. Concluimos este apartado con la figura 9 donde se 


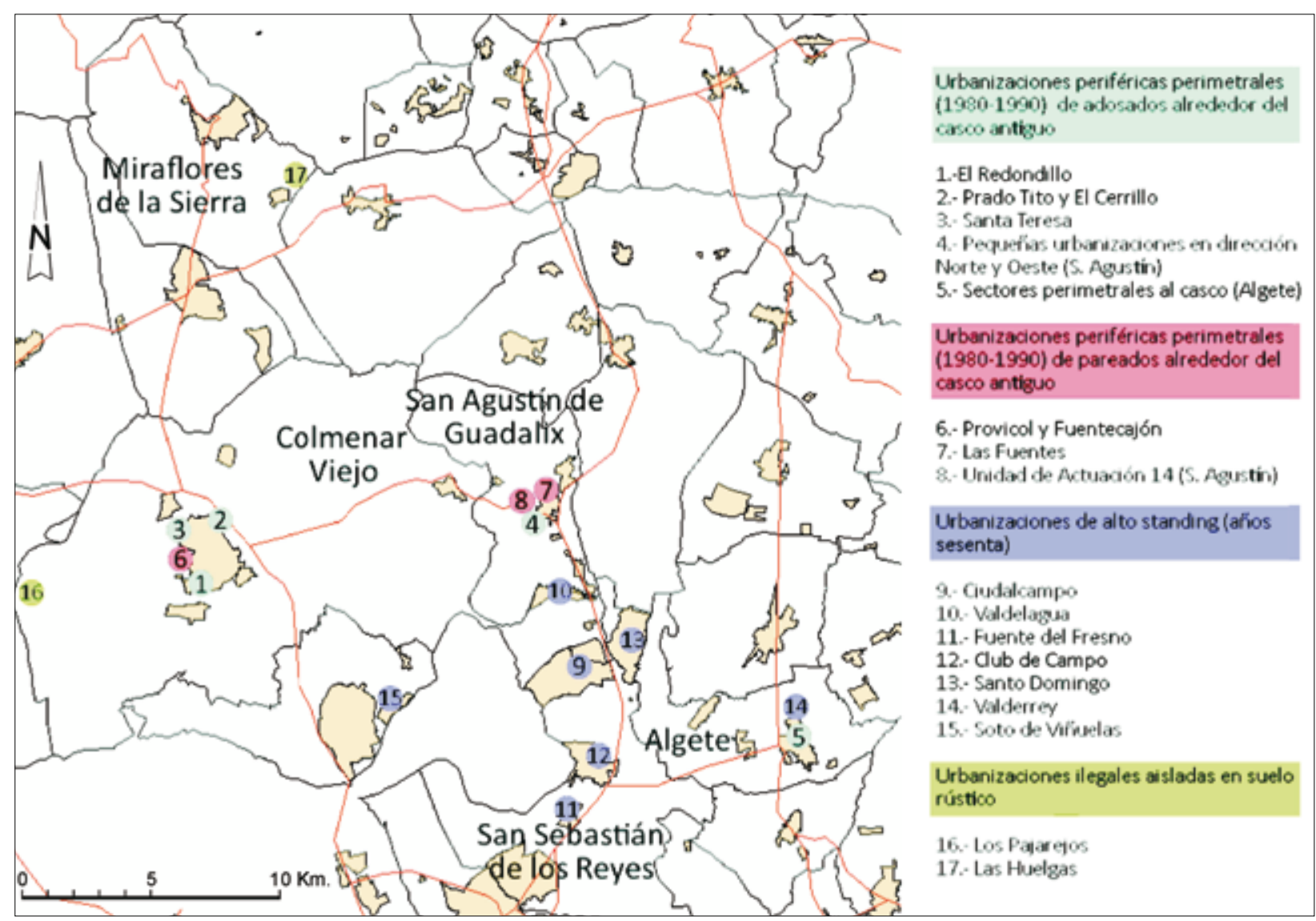

Fig. 12. Ejemplos extrapolables a municipios limítrofes. Fuente: Cartociudad y archivo shape del Departamento de Geografía Humana de la UCM. Elaboración propia con la colaboración de Juan de la Puente.

representan todos los asentamientos de vivienda unifamiliar mencionados hasta aquí13.

\section{ASPECTOS EXTRAPOLABLES A OTROS MUNICIPIOS}

Por sus características peculiares Colmenar Viejo presenta un abanico de ejemplos de actuaciones de vivienda unifamiliar, algunos de los cuales son muy típicos de centros comarcales con tradición rural y rasgos recientes de núcleo dormitorio y otros que podemos encontrar en los municipios limítrofes. Sin embargo, hay algunos, como las antiguas colonias de veraneo (por ejemplo Dos Castillas o San Crispín) destinadas a clases medias-bajas,

\footnotetext{
13 De los ámbitos de desarrollo del plan general vigente sólo se incluyen los
} que tienen su plan parcial ya aprobado. que son muy típicos de Colmenar, diferenciándose de las segundas residencias de los municipios de la sierra de Guadarrama por su menor calidad constructiva y el nivel socioeconómico a que se orientan. También hacia el este nos encontramos con municipios como San Sebastián de los Reyes y Alcobendas que son muy diferentes por su desarrollo histórico y por haber alcanzado un nivel de multifuncionalidad y de generación de empleo muy superiores.

No obstante, se han podido encontrar algunos ejemplos de tipos específicos de actuaciones residenciales en algunos municipios limítrofes. En este caso los criterios utilizados para la selección de dichos ejemplos han sido los siguientes: contigüidad territorial con el término municipal de Colmenar Viejo; similitud morfotipológica de los núcleos urbanos (núcleo que tenga una almendra central constituida por su casco antiguo con trazado viario de origen rural y una o más coronas de desarrollos posteriores con vivienda unifamiliar); coetaneidad de los 


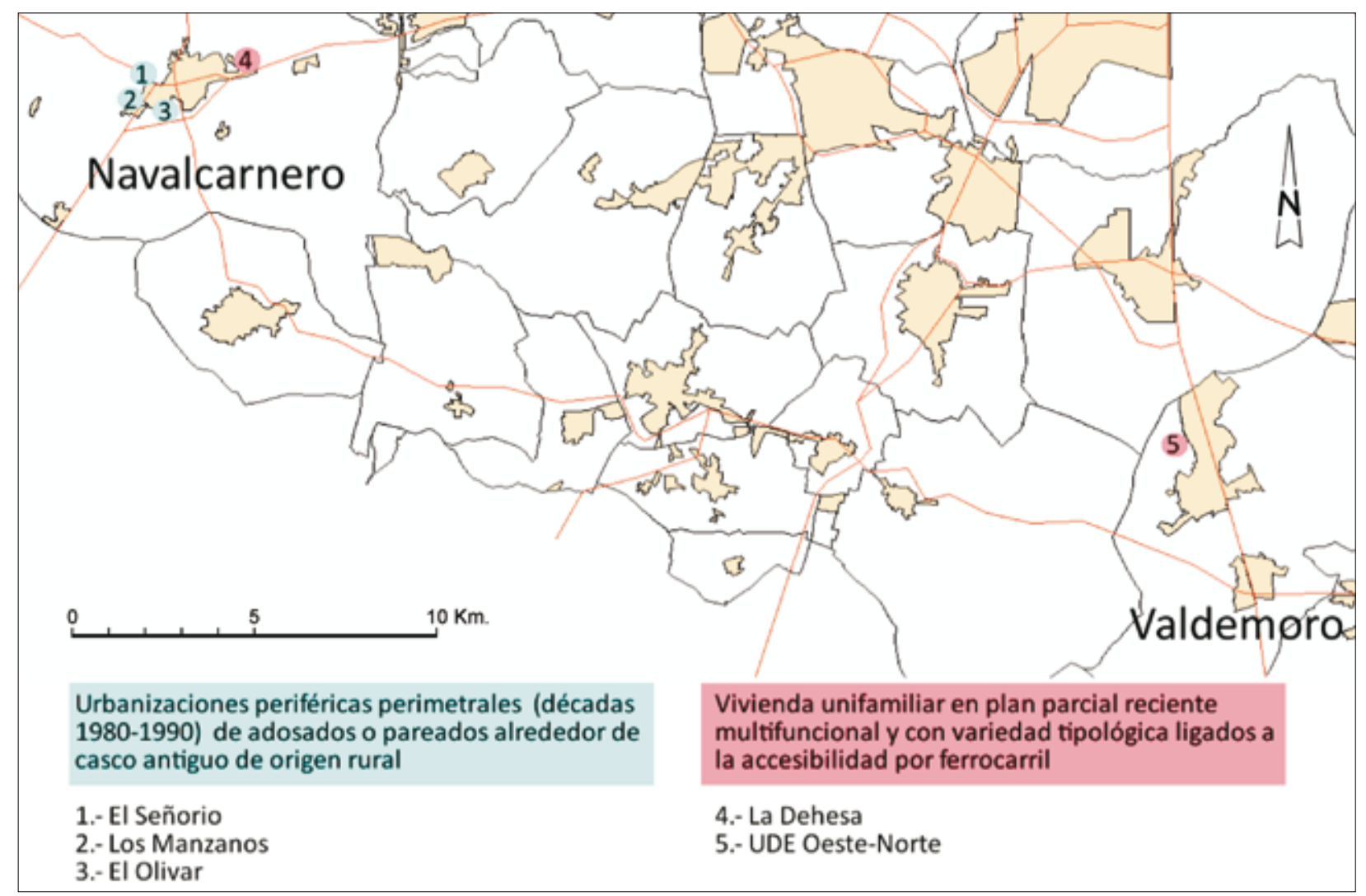

FIG. 13. Ejemplos extrapolables a municipios del mismo eje temático. Fuente: Cartociudad y archivo shape del Departamento de Geografía Humana de la UCM. Elaboración propia con la colaboración de Juan de la Puente.

ejemplos comparados. El caso de San Agustín de Guadalix es emblemático. A pesar de no tener históricamente el mismo estatus a nivel comarcal y de tratarse de un centro de tamaño más reducido, se ha podido observar la presencia de una almendra central con trazado viario de origen rural alrededor de la cual se han producido desarrollos compactos y pequeños de urbanizaciones periféricas perimetrales de adosados y pareados alrededor de las décadas de 1980 y 1990. La vivienda unifamiliar tiene en San Agustín un desarrollo más reciente a en Colmenar; por eso en el cuadro 12 se han incluido únicamente las urbanizaciones coetáneas y con tipología edificatoria parecida. De los municipios colindantes parece ser éste el más representativo respecto a otros municipios serranos que resultan demasiado pequeños o más parecidos a los antiguos desarrollos de segunda residencia del corredor de la A-6. En el mismo período y también en la primera década del siglo XXI se produce un fenómeno similar en Algete, donde se crea una serie de sectores de vivienda unifamiliar mayoritariamente adosada, que se configuran como extensiones perimetrales del casco antiguo.
Por lo que concierne a las urbanizaciones de alto standing separadas física y urbanísticamente del núcleo histórico de Colmenar, en este caso más por su carácter metropolitano que local ha sido más fácil encontrar ejemplos similares en los municipios próximos. Un caso muy particular lo aportan las urbanizaciones colmenareñas de alto nivel que se extienden por otros municipios colindantes, ejemplificadas en Ciudalcampo y Valdelagua. Al mismo grupo pertenece Soto de Viñuelas, que hoy se encuentra en el independizado municipio de Tres Cantos. Completan este subgrupo tres ejemplos de San Sebastián de los Reyes (donde, además de Ciudalcampo, existen las urbanizaciones Fuente del Fresno y Club de Campo) y Algete, donde se ubican la urbanización Santo Domingo y la Ciudad Jardín Valderrey.

En cuanto a la presencia de parcelaciones ilegales, en Colmenar se registran dos actuaciones para residencia secundaria sobre parcelas de gran tamaño, una de las cuales destinada a clases altas (Los Chortales) y otra a clases medias-bajas (Los Pajarejos). Estudiando los ejemplos contenidos en el Catálogo de Urbanizaciones Ilegales pu- 


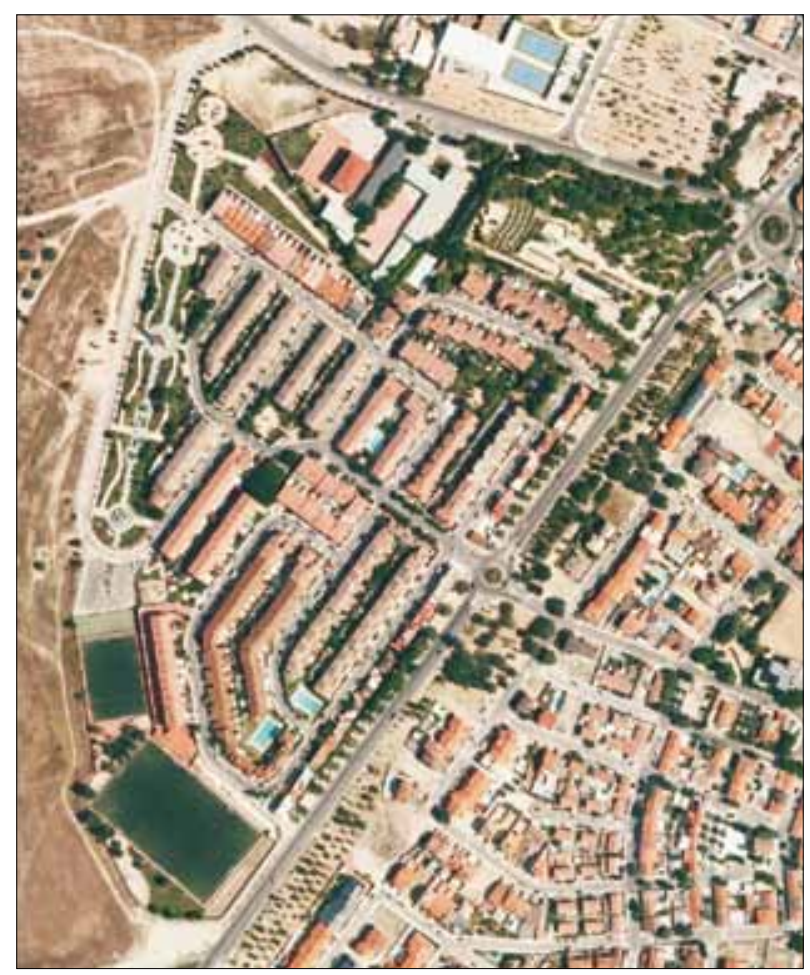

Fig. 14. Barrio de El Señorío en Navalcarnero (vista aérea, 2011). Fuente: Planea, visor cartográfico de la Comunidad de Madrid.

blicado en 1984 por la Consejería de Ordenación del Territorio, Medio Ambiente y Vivienda de la Comunidad de Madrid, en los alrededores de Colmenar el único ejemplo de urbanización ilegal aislada en suelo rústico para segunda residencia y con tipología de trazado viario parecida a las mencionadas es la de Las Huelgas (Miraflores de la Sierra), a pesar de su tamaño más reducido. En el catalogo se pueden encontrar otros ejemplos en la zona, sin embargo tienen características muy diferentes a las de Colmenar, siendo suficiente el hecho de que varios de ellos adoptan un trazado viario mucho más organizado.

En el mismo eje temático en que se encuadra el municipio de Colmenar Viejo (la vivienda unifamiliar en centros híbridos entre capital comarcal y pueblo dormitorio), se encuadran otros municipios de similares características aunque en localización alejada de Colmenar: Navalcarnero y Valdemoro (Fig. 13).

En estos dos municipios se han encontrado ejemplos de urbanizaciones periféricas de adosados o pareados perimetrales al casco antiguo de origen rural, construidas entre los años ochenta y noventa del siglo xx. Este es el caso de los barrios de El Señorío, Los Manzanos y El Olivar en Navalcarnero. También hemos rastreado ejemplos similares al nuevo Barrio de La Estación de Colmenar Viejo, caracterizados por la vivienda unifamiliar incluida en planes parciales recientes de carácter multifuncional y con variedad tipológica, y por la accesibilidad por ferrocarril existente o prevista. Se han detectado dos ejemplos recogidos en el cuadro 13: La Dehesa de Navalcarnero y la UDE oeste-norte de Valdemoro, siendo la segunda más parecida por el tamaño de la actuación y el nivel de diversificación funcional-tipológica; sin embargo, ambos se apoyaron en el momento de la redacción del proyecto en sendas estaciones de ferrocarril que todavía en el año 2014 no han visto la luz.

Es interesante notar cómo ambos ejemplos son unidades de desarrollo equilibrado, cuyo concepto deriva del documento de las bases del Plan Regional de Estrategia Territorial de 1996. Entre los criterios en que se basaba el planteamiento original de esta idea destacan:

[...] apoyarse en un centro urbano existente, y una dotación de accesibilidad al ferrocarril de cercanías; desarrollar una morfología de características urbanas y con transiciones desde las zonas edificadas hacia los espacios libres, con baja densidad; orientarse a uso mixto del suelo, con proximidades y espacios de relación; dotarse del máximo de autonomía de servicios que la dimensión de la población permita. (Comunidad de Madrid, 1996, p. 66).

De estos criterios podemos extraer los conceptos de multifuncionalidad y baja densidad (que normalmente se asocia a la vivienda unifamiliar), aunque quizás sería más correcto en los ejemplos citados hablar de densidad media, sobre todo por la existencia de bloques de vivienda colectiva, como los dos elementos que mejor pueden resumir la presencia de la vivienda unifamiliar en un plan parcial con variedad de tipología y usos. Justamente estos son los rasgos que hemos encontrado tanto en el barrio de La Estación de Colmenar como en los ejemplos de Navalcarnero y Valdemoro.

\section{CONCLUSIONES}

El caso de estudio presentado en este trabajo representa un ejemplo significativo de desarrollo de vivienda unifamiliar en la comunidad de Madrid, situado en un entorno históricamente relevante alrededor de un núcleo urbano preexistente con funciones de capital comarcal. El análisis de un abanico suficientemente amplio de asentamientos a distintas escalas nos ha permitido comprender cómo el hábitat unifamiliar en esta zona de la región metropolitana de Madrid se caracteriza por la localización mayoritaria de los asentamientos alrededor del casco an- 


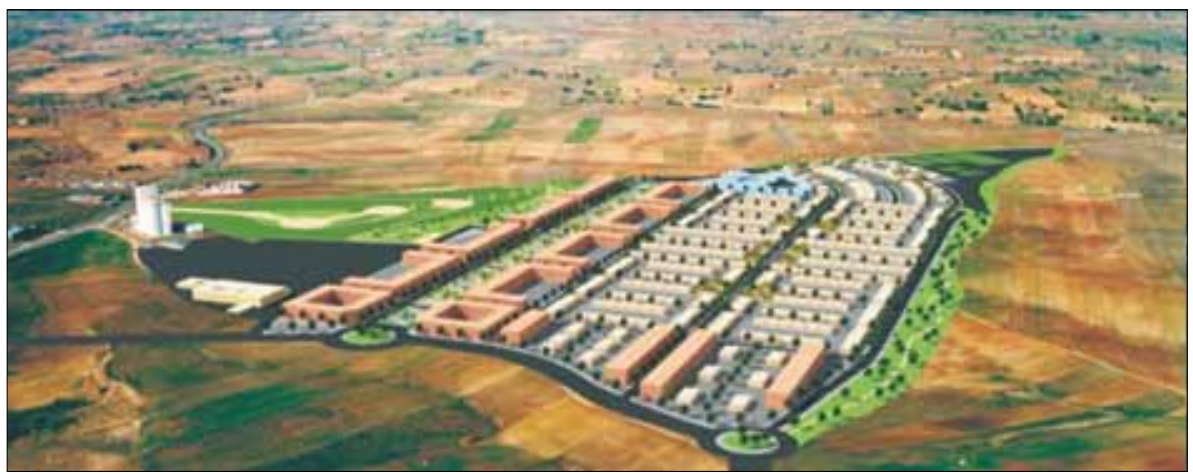

FIG. 15. La Dehesa de

Navalcarnero (maqueta). Fuente:

García Uyarra (2005, p. 150).

tiguo, excepto algunas urbanizaciones geográficamente situadas en una localización más aislada. Este aspecto nos permite dejar constancia de una característica fundamental del modelo de difusión metropolitana madrileño, que se plasma adoptando una forma de difusión concentrada. Probablemente, habría que replantearse la cuestión de la difusión residencial sin vincularla necesariamente a la tradicional contraposición entre ciudad dispersa y compacta, ya que el caso de la región metropolitana de Madrid demuestra cómo los procesos de difusión pueden dar lugar a desarrollos relativamente compactos. La compacidad de los asentamientos está íntimamente ligada a otro tema clave del debate sobre la dispersión residencial, es decir la densidad. Por regla general, el modelo de difusión residencial madrileño no se caracteriza, al contrario del sprawl norteamericano, por la baja densidad edificatoria. La mayor parte de los desarrollos de vivienda unifamiliar de la región metropolitana de Madrid oscilan entre densidades medias-bajas o incluso medias, predominando éstas en los asentamientos más recientes. Esta característica se encuentra también en el caso de estudio seleccionado, es decir Colmenar Viejo. La localización mayoritaria de los desarrollos residenciales de Colmenar en las inmediaciones del casco antiguo y su relativa compacidad, junto con la presencia de infraestructuras y equipamientos ligados a la capitalidad comarcal histórica de ese pueblo, lo configuran como un núcleo que potencialmente se puede convertir en un sub-centro metropolitano, aunque dicha condición se encuentra todavía en una fase incipiente. La evolución hacia un patrón post-suburbano (Phelps y otros, 2006) o de miniciudad suburbana (Røe y Saglie, 2011) podría plantearse como respuesta al modelo de desarrollo residencial metropolitano monofuncional. Para reorientar el modelo de difusión residencial madrileño hacia un patrón de sostenibilidad urbana homologable a las tendencias contemporáneas en materia de políticas urbanas y planeamiento urbanístico hay que apostar por la multifuncionalidad. Las tendencias más recientes del desarrollo de la vivienda unifamiliar en la región metropolitana de Madrid, representadas en el caso de Colmenar Viejo por el Consorcio Urbanístico de La Estación, permiten destacar la importancia de la integración de distintos usos y funciones urbanas en el mismo asentamiento. Esta característica, aunque no siempre da lugar a una completa autosuficiencia de los asentamientos, incrementa la animación del lugar y su sentido de urbanidad. Además, la existencia de ejemplos antecedentes al de La Estación, con rasgos de multifuncionalidad, como el sector de Santa Teresa, deja constancia de cómo sea posible intervenir sobre el territorio mediante proyectos de tamaño más reducido respecto a las grandes actuaciones realizadas en la época del boom inmobiliario, inviables en la actualidad. En periodos de crisis, hay que reflexionar sobre la viabilidad económica de los proyectos, la efectiva demanda de viviendas y servicios a satisfacer así como la sostenibilidad social y medioambiental de las actuaciones. La identificación de la escala o tamaño de proyecto más adecuado, acorde con el contexto local, representará indudablemente un factor esencial a tener en cuenta de cara al futuro. Partiendo del carácter histórico de Colmenar Viejo como capital comarcal y considerando su peso poblacional y territorial, se podrá así implementar un cierto grado de mezcla funcional, sin meter en riesgo la identidad tradicional del lugar.

\section{BIBLIOGRAFÍA}

Ayala y Raya, M. (1890): Colmenar Viejo. Biblioteca de la Provincia de Madrid: crónica general de sus pueblos. T. IV, Diputación Provincial de Madrid, Madrid. Ayuntamiento de Colmenar Viejo (1987), Memoria del Plan General de Ordenación Urbana. Colmenar Viejo, pp. 35-150. 
- (2002): Memoria del Plan General de Ordenación Urbana. Colmenar Viejo.

CAnto C. del (1987): «Esquema interpretativo de la producción de espacios turísticos residenciales madrileños». Anales de Geografía de la Universidad Complutense, núm. 7, pp. 389-398.

ComunidAd DE MADRID (1984): Urbanizaciones ilegales. Catálogo. Consejería de Ordenación del Territorio, Medio Ambiente y Vivienda, Madrid.

- (1991), Arquitectura y desarrollo urbano. Comunidad de Madrid zona centro. Tomo II. Dirección General de Vivienda y Rehabilitación, Madrid.

- (1996): Plan Regional de Estrategia Territorial. Bases. Consejería de Obras Públicas, Urbanismo y Transportes, Madrid.

- (2006): Síntesis del sig de los planes generales de $13 \mathrm{mu}$ nicipios. Ámbito metropolitano. Consejería de Medio Ambiente y Ordenación del territorio, Madrid, inédito.

Coplaco (Comisión de Planeamiento y Coordinación del Área Metropolitana de Madrid) (1979): paI Norte. Estudio urbanístico del municipio de Colmenar Viejo. Planeamiento vigente y patrimonio sector público. Madrid.

- (1981): Documento de difusión y debate. PAI de Colmenar Viejo. Madrid.

eeA (Agencia Europea de Medio Ambiente) (2006): Urban Sprawl, the ignored challenge. <www.eea. europa.eu/publications/eea_report_2006_10>. [Consulta: 9 de junio de 2014.]

FERNÁNDEZ F. (1986): La franja periurbana de Gijón. Consejería de Ordenación del Territorio, Vivienda y Medio Ambiente del Principado de Asturias/Ayuntamiento de Gijón/Banco de Bilbao.

GARcía UyARrA, A. (2005): «Las actuaciones residenciales de Arpegio: entre la centralidad y la suburbanización». Urban, núm. 10, pp. 130-150.

IndOVInA, F. (1990): La città diffusa. DAEST, Venecia.

LeAl, J., y J. CoRTÉs (1995): La vivienda en Madrid. Análisis espacial de la dinámica residencial en la región.
Consejería de Política Territorial, Comunidad de Madrid, Madrid.

LÓPEZ DE LUCIO, R. (2003): «Transformaciones territoriales recientes en la región urbana de Madrid». Urban, núm. 8,pp. 124-161.

Monclús, F. J. (ed.) (1998): La ciudad dispersa. Centro de Cultura Contemporània de Barcelona, Barcelona.

Phelps, N., y otros (2006): Post-Suburban Europe: Planning and Politics at the Margins of Europe's Capital Cities.Palgrave MacMillan, Basingstoke.

Ponce Herrero, G. (2006): La ciudad fragmentada. Nuevas formas de hábitat. Universidad de Alicante, Alicante.

RøE, P. G., e I.-L. SAGLIE (2011) «Minicities in suburbia. A model for urban sustainability?». FORMakademisk, núm. 4 (2), pp. 38-58.

Santiago, E. de (2007): «Madrid, “ciudad única”. Pautas y lógicas espaciales recientes en la región madrileña». Urban, núm. 14, pp. 8-33.

Soule, D. C. (ed.) (2005): Urban Sprawl: A Comprehensive Reference Guide. Greenwood Press, Westport, Connecticut.

Valenzuela Rubio, M. (1977): Urbanización y crisis rural en la sierra de Madrid. Instituto de Estudios de Administración Local, Madrid.

- (2003): «La residencia secundaria en ámbitos metropolitanos: La Comunidad de Madrid». Estudios Turísticos, núm. 155-156, pp. 112-157.

- (2011): «Los procesos de metropolización. Madrid, una región metropolitana entre la dispersión y el policentrismo», en F. Humbert, F. Molinero y M. Valenzuela (eds.): España en la Unión Europea. Un cuarto de siglo de mutaciones territoriales. Collection de la Casa de Velázquez, Madrid, 121, pp. 211-253.

Whyte, W. H. Jr. (1958): «Urban Sprawl», en The exploding metrópolis. Doubleday.

ZÁrATE, M. A. (2003): «Madrid, un modelo suprametropolitano de urbanización». Anales de Geografía de la Universidad Complutense, núm. 23, pp. 283-304. 